

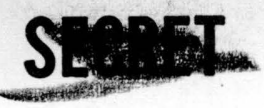

Technical Repart 42 JULY, 1956

\section{Testing of a Compacted Snow Runway (U)}

by James A. Bender

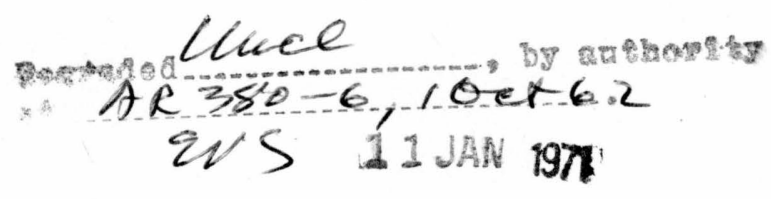

\section{GROUP - 4}

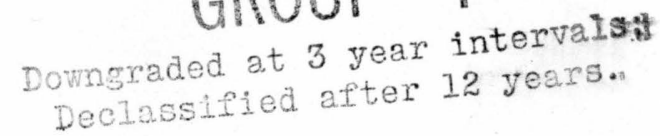

SNOW, ICE AND PERMAFROST RESEARCH ESTABLISHMENT Carpe of Engineere. U. S. Army 


\section{PREFACE}

This report describes the methods and techniques used in testing a snow runway built on deep snow on the Greenland Ice Cap during the summer of 1955. The runway was built by members of the 1st Engineer Arctic Task Force, commanded by Lt. Col. Elmer P. Clark and under the immediate supervision of Capt. John Napier, with $\mathrm{Mr}$. Paul Beigbeder of the Engineer Research and Development Laboratories, Corps of Engineers, as project engineer. Mr. James A. Bender, Chief of the Snow and Ice Basic Research Branch, Snow Ice and Permafrost Research Establishment, was responsible for the testing of the strip, aided by members of the lst Engineer Arctic Task Force, especially Pfc Frank Royse. The information regarding the landings of the C-124 was obtained from Lt. W. H. McTigue, who was an official observer of the lst EATF.

Ms. received 4 June, 1956

Department of the Army Project No. 8-66-02-004 


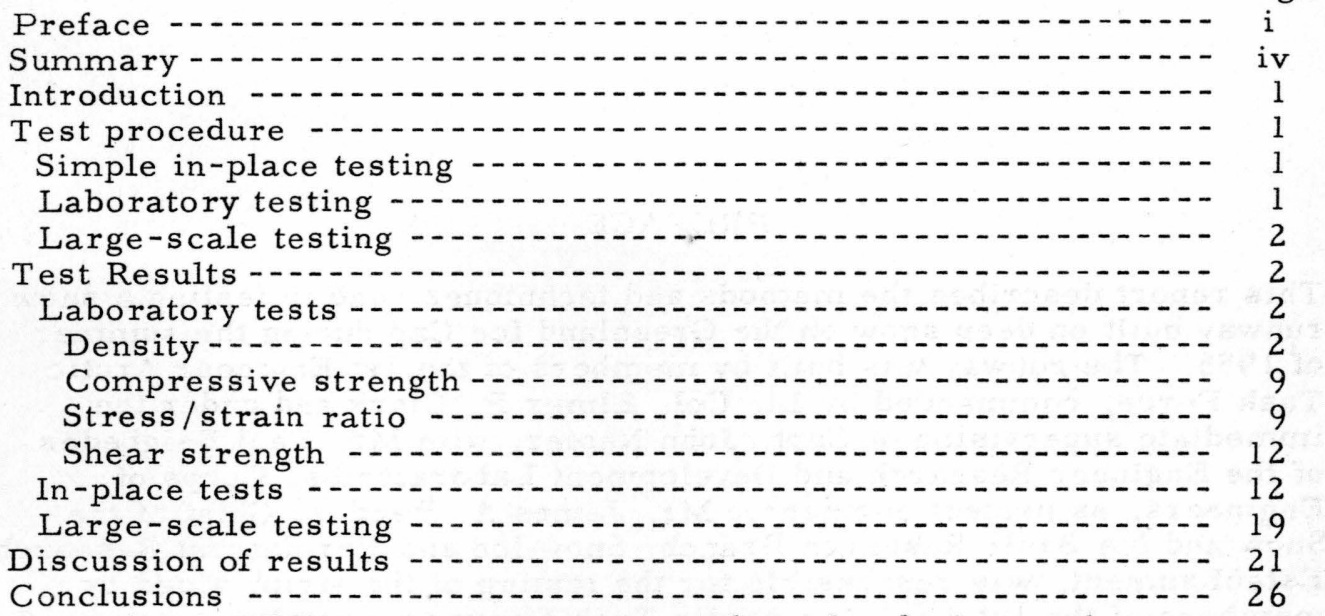

Appendix A. Effects of temperature and age hardening on the strength of snow.

References

Appendix B. Preliminary instructions for determining whether a specific aircraft can land safely on a given compacted airstrip

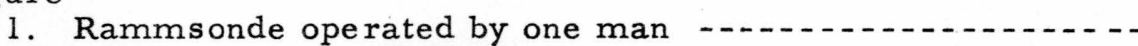

2. Daily air temperatures

3. SIPRE modified 3-in auger

4. Press for testing strength of snow samples

5. Bros rubber-tired roller

6. Ski-wheeled $\mathrm{C}-47$ airplane on strip

7. C-54 airplane on strip

8. C-124 airplane on strip

9. Division of processing of the strip into sections

10. a) Variation of density with depth and position

b) Variation of density with depth and position

11. Density and temperature profile of snow before processing

12. Compressive strength vs. depth, Sections I and II

13. Compressive strength vs. depth, Section III -

14. Compressive strength vs. depth, Section IV

15. Compressive strength vs. depth, Section V

16. Compressive strength vs. depth, Section VI -

17. Type of break of specimen under compression

18. Stress-strain curves for four typical specimens -.-.-.-

19. Stress/strain ratio with depth, Section IV

20. Stress/strain ratio with depth, Section VI -...-

21. Ram hardness vs. depth, Section I-...-

22. Ram hardness vs. depth, Section II

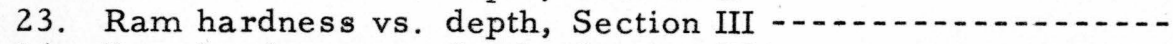

24. Ram hardness vs. depth, Section IV

25. Ram hardness vs. depth, Section V

Page
1
2
2
4
4
4
4
5
5
6
7
8
8
8
8
8
8
9
10
11
11
12
13
13
14
14


26. Ram hardness vs. depth, Section VI

27. Ram hardness from 0-10 cm depth vs $10-15 \mathrm{~cm}$ depth

28. Average ram hardness by layer, Section I - 16

29. Average ram hardness by layer, Section II -

30. Average ram hardness by layer, Section III -

31. Average ram hardness by layer, Section IV

32. Average ram hardness by layer, Section V

33. Average ram hardness by layer, Section VI

34. Tractors pulling Bros roller out of breakthrough

35. Sketch of manner of surface failure

36. Difference in homogeneity of samples from sections III and IV 20

37. Large iced snow clumps from Section III _. 20

38. Average density, compressive strength, and ram hardness by layer, Section III - 23

39. Average density, compressive strength, and ram hardness by layer, Section IV - 23

40. Average density, compressive strength, and ram hardness by layer, Section V-... 24

41. Average density, compressive strength, and ram hardness by layer, Section VI - 24

42. Ram hardness versus compressive strength

43. Ram hardness vs. support or failure of aircraft

44. Stress distribution with depth of various aircraft

Al. Strength vs. temperature plot on a $\log -\log$ scale

A2. Temperature affect on tensile strength of various grained snow - -

A3. Work required to disaggregate snow vs. days of agehardening

A4. Ratio of strength increase vs. days of age-hardening ----- A2

\section{SUMMARY}

A snow runway was built on deep snow on the Greenland Ice Cap and tested during the summer of 1955 . The strip was constructed by members of the lst Engineer Arctic Task Force using modified pulvimixers with heat. Testing included Rammsonde measurements, and snow temperature observations on the strip; undisturbed cores were taken and tested for density, structure, unconfined compressive strength, unconfined shear strength, and stress/strain relations. Large-scale testing was done with a Bros rubber-tired roller, and C-47, C-54 and C-124 type aircraft. A formulation between the ram hardness values and the unconfined compressive strength is developed, and the Rammsonde is suggested as a simple instrument for determining the bearing capacity of a snow. Formulas are given for the increase in strength of snow with decreasing temperature and also for the amount of age-hardening with time. 


\section{INTRODUCTION}

The processing of the snow for the runway, by modified pulvimixers using heat, was started on $6 \mathrm{July}$ and completely finished by 1 September. Successful landings on the $200 \times 10,000 \mathrm{ft}$ strip were made by $\mathrm{C}-47, \mathrm{C}-54$, and $\mathrm{C}-124$ type aircraft. The conclusion that the strip could support the se aircraft and the decision to land the planes we re based on the laboratory testing.

This report describes the methods and techniques used in testing a snow runway built on deep snow, and gives suggested requirements of a snow runway to support various type aircraft. It is not intended as a report on the operational aspects of making such a runway, nor as a critique on the techniques used. Also, it should be realized that this represents the beginning of a long-range program and that additional theoretical work and field work are still necessary.

\section{TEST PROCEDURE}

The testing procedure may be divided into three methods: (a) simple in-place testing, (b) the taking of undisturbed samples and testing them in a laboratory, and (c) large-scale testing. Procedures (a) and (b) require only two men and simple testing equipment. It is desirable that procedure (a) perhaps supplemented by (b) give sufficient information to predict the results of large-scale tests and the capabilities of a snow runway.

\section{Simple in-place testing}

A large number of ram hardness readings were made systematically on the strip several times during the test period. The Rammsonde (see discussion by R. Haefeli, in Bader et al, 1939, Ch. II) is a simple instrument which requires only one man to operate and another to take readings (see Fig. 1), and one profile was obtained in about 5 minutes. Several pits were dug in the runway and the temperature-depth profile obtained using Weston dial thermometers. Daily air temperatures (Fig. 2) during the period were obtained from the Air Force.

\section{Laboratory testing}

A laboratory was made by the simple expedient of digging a $6 \times 8 \times 8$-ft deep hole in the snow and covering it with a few $2 \times 6$-in boards and a tarpaulin. The roof was soon covered by a foot of drifted snow. This provided an ample working space protected from the elements and at a temperature of about $-10^{\circ} \mathrm{C}\left(14^{\circ} \mathrm{F}\right)$. Undisturbed specimens for testing were obtained from the strip with the SIPRE modified auger (Fig. 3). Vertical cores 3 in. $(7.6 \mathrm{~cm})$ in diameter and up to $34 \mathrm{in.}(86 \mathrm{~cm})$ long were obtained. The procedure used was to take several cores, noting the position on the strip for each one, place them individually in cardboard tubes, and transport them to the snow laboratory. Here, each core was visually inspected and the depth of each layer and its structure noted. The core was then cut into sections with a simple miter box and saw. Cuts were made at layer boundaries, with a maximum length of 10 in. $(25 \mathrm{~cm})$ the largest size useable in the specially designed press (Fig. 4). The exact diameter, length, and

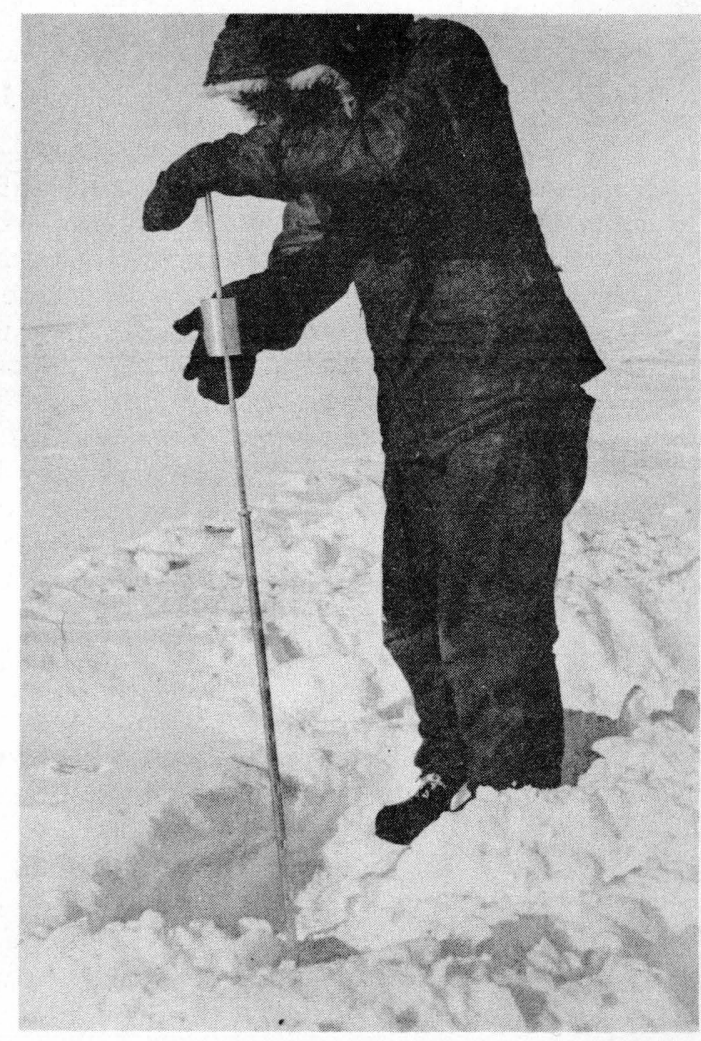

Figure 1. Rammsonde operated by one man. 


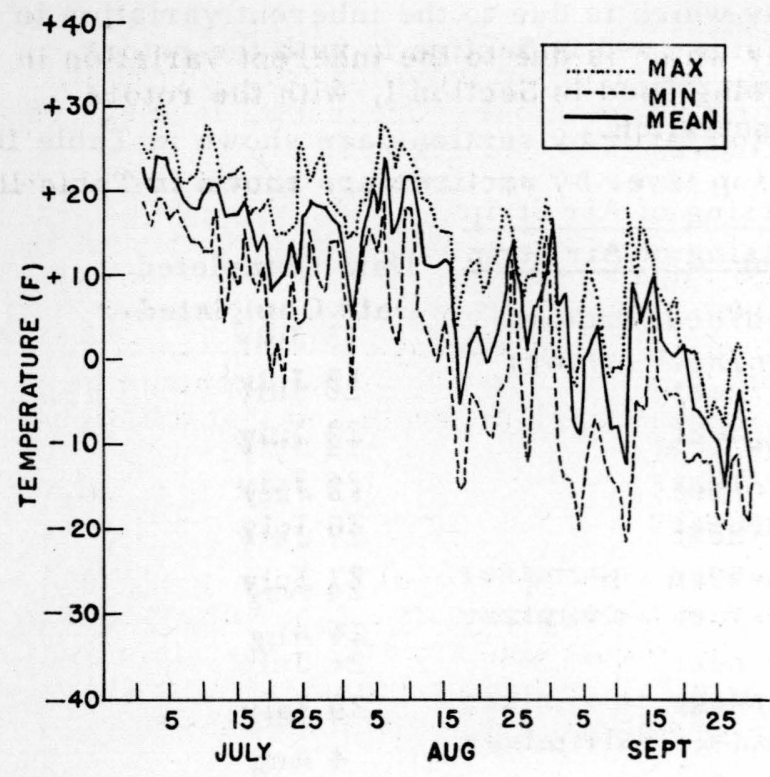

Figure 2. Daily air temperature.

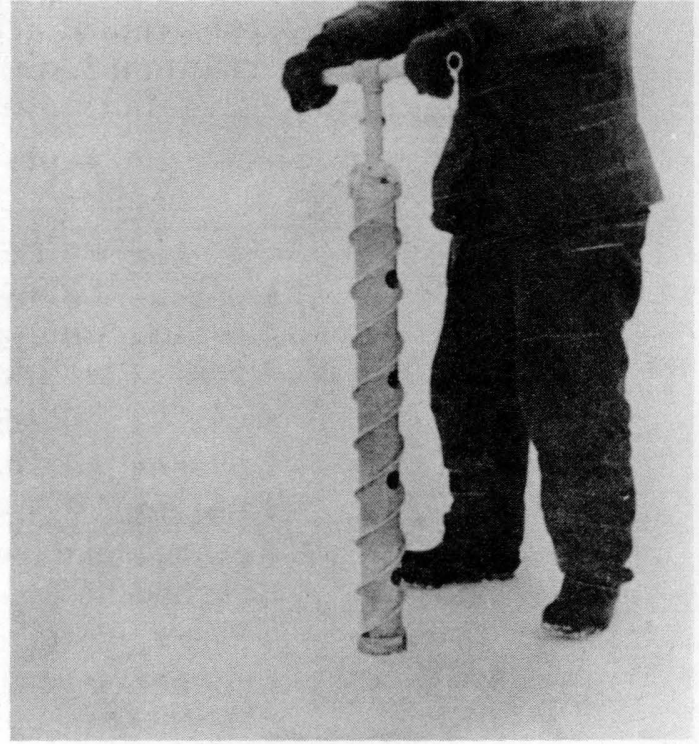

Figure 3. SIPRE modified 3-in auger.

weight of each cut portion were measured in order to obtain the density with depth. Whenever possible, the ultimate unconfined compressive strength and stress-strain relationship were obtained, with the rate of loading and temperature noted.

In addition to the vertical sampling, four pits were dug and horizontal core samples taken for shear measurements. The depth, structure, density, and ultimate shear strength (zero lateral pressure) of each specimen were obtained, with the rate of loading and temperature noted.

\section{Large-scale testing}

A four-wheeled rubber-tired Bros roller (Fig. 5) was pulled over the entire strip, first empty, and then with increasing load up to 13,000 lb per wheel with approximately 100 psi tire pressure. The areas where breakthrough occurred were noted and studied. Readings were taken with a rod and transit to determine whether or not there was any deflection of the strip (due to plate action) when the tractor and roller passed by.

The final testing was the successful landings and take-offs of C-47, C-54, and C-124 type aircraft (Figs. 6, 7, and 8).

\section{TEST RESULTS}

The processing of the snow is summarized in Table I. All sampling was done three or more days after processing. The division of the strip into sections is shown in Figure 9.

\section{Laboratory tests}

Density. The densities with depth and position on the strip are shown in Figure 10. It was noted that the processing caused a hard top layer of high density and strength; below it, the density decreased from that of the top layer to that of the virgin snow. The hard uppermost layer was caused by disaggregating action of the pulvimixer and the heating of the snow with the resultant free moisture and their freezing. The second layer's increased density is partly due to the pulvimixer action and partly to compaction by a loaded skid which followed. The densities (specific gravities) are considered to be accurate to 0.01 . It may also be noted that the depth 
of the processed layer varies considerably which is due to the inherent variation in pulvimixer action. The method of processing used in Section I, with the rotors running backwards, gave much deeper penetration.

The average density and depth of the top layer by sections are shown in Table II.

Table I. Processing of Air Strip

\begin{tabular}{|c|c|}
\hline Section & Processing \\
\hline I & $\begin{array}{l}6 \text { passes pulvimixer wo/heat (rotors } \\
\text { turning backwards) } \\
3 \text { passes pulvimixer w/heat }\end{array}$ \\
\hline II & $\begin{array}{l}3 \text { passes pulvimixer wo/heat } \\
3 \text { passes pulvimixer } \mathrm{w} / \text { heat }\end{array}$ \\
\hline III & $\begin{array}{l}3 \text { passes pulvimixer w/heat } \\
\text { Reprocessed using } 3 \text { passes pulvimixer } \\
\text { w/heat }\end{array}$ \\
\hline IV & $\begin{array}{l}3 \text { passes pulvimixer } \mathrm{w} / \text { heat } \\
\text { Reprocessed using } 3 \text { passes pulvimixer } \\
\text { w/heat }\end{array}$ \\
\hline $\mathrm{V}$ & $\begin{array}{l}3 \text { passes pulvimixer } \mathrm{w} / \text { heat } \\
\text { Reprocessed using } 3 \text { passes pulvimixer } \\
\text { w/heat } \\
\text { Old processed snow removed, virgin } \\
\text { snow brought in and processed with } \\
3 \text { passes of pulvimixer w/heat }\end{array}$ \\
\hline VI & 3 passes pulvimixer $\mathrm{w} /$ heat \\
\hline
\end{tabular}

Date Completed

15 July

20 July

$12 \mathrm{July}$

$20 \mathrm{July}$

27 July

24 Aug

26 July

4 Aug

11 Aug

22 Aug

1 Sept

10 Aug

\section{Table II. Average Density of Processed Layer}

\begin{tabular}{cccc} 
Section & $\begin{array}{c}\text { Average } \\
\text { Density } \\
\left(\mathrm{g} / \mathrm{cm}^{3}\right)\end{array}$ & \multicolumn{2}{c}{$\begin{array}{c}\text { Average Depth of } \\
\text { Processed Layer } \\
(\mathrm{cm})\end{array}$} \\
I & .60 & 49 & 19 \\
II & .57 & 23 & 9 \\
III & .60 & 38 & 15 \\
IV & .55 & 28 & 11 \\
V & .58 & 39 & 15 \\
V* & .59 & 43 & 18 \\
VI & .56 & 26 & 10
\end{tabular}

The virgin snow was generally about $76 \mathrm{~cm}$ (30 in.) below the top of the processed layer and had a density of about 0.42 . The density of the snow between the processed and virgin layer decreased with depth. The density and temperature profile of the snow before processing are shown in Figure 11.

* On virgin snow that was hauled in and processed. 


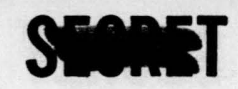

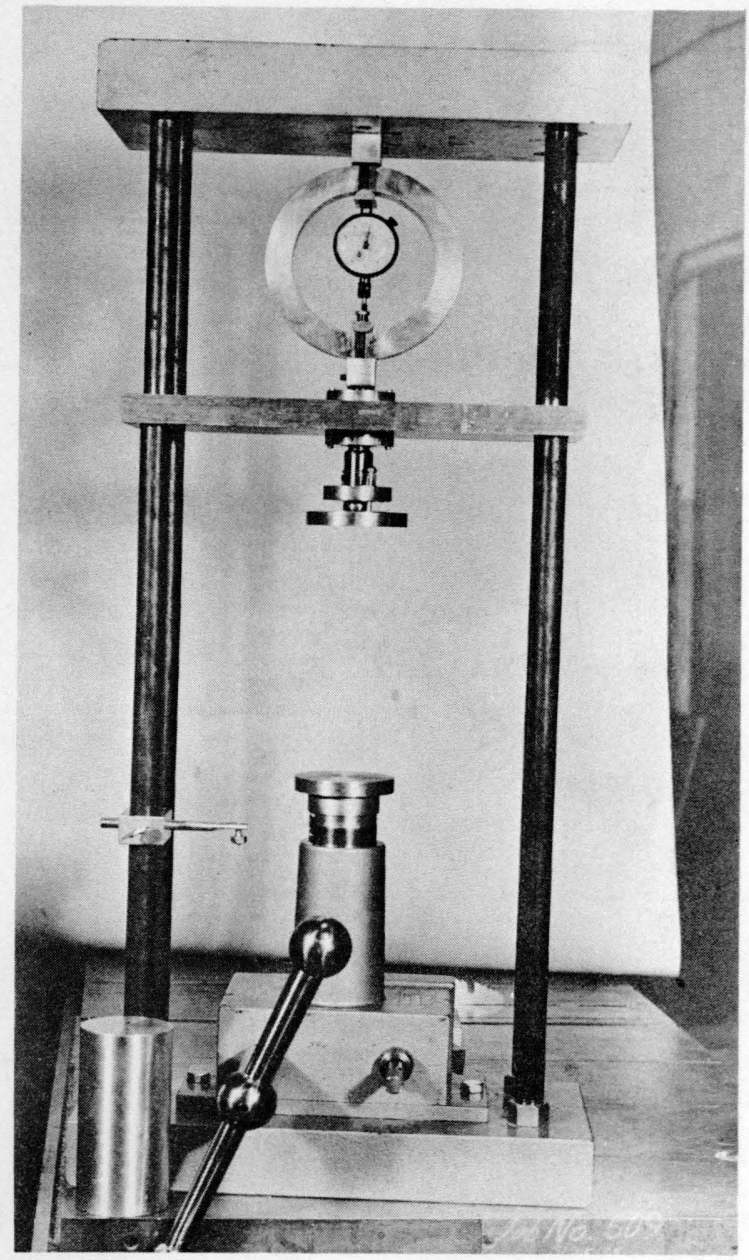

Figure 4. Press for testing strength of snow samples.

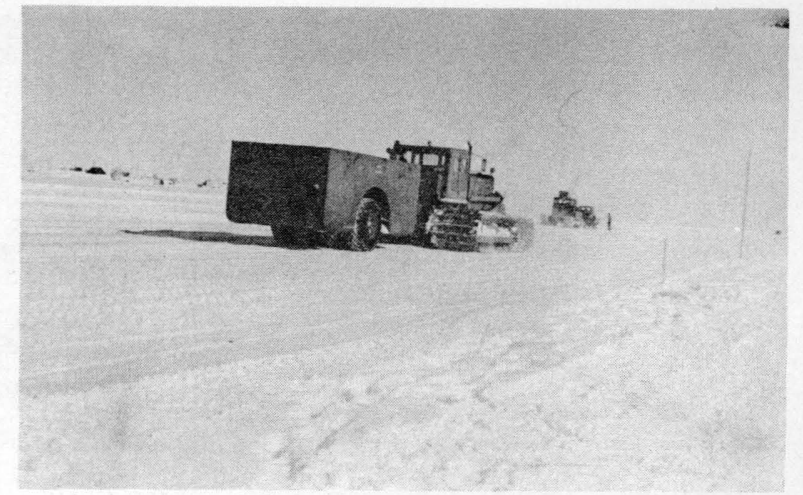

Figure 5. Bros rubber-tired roller.

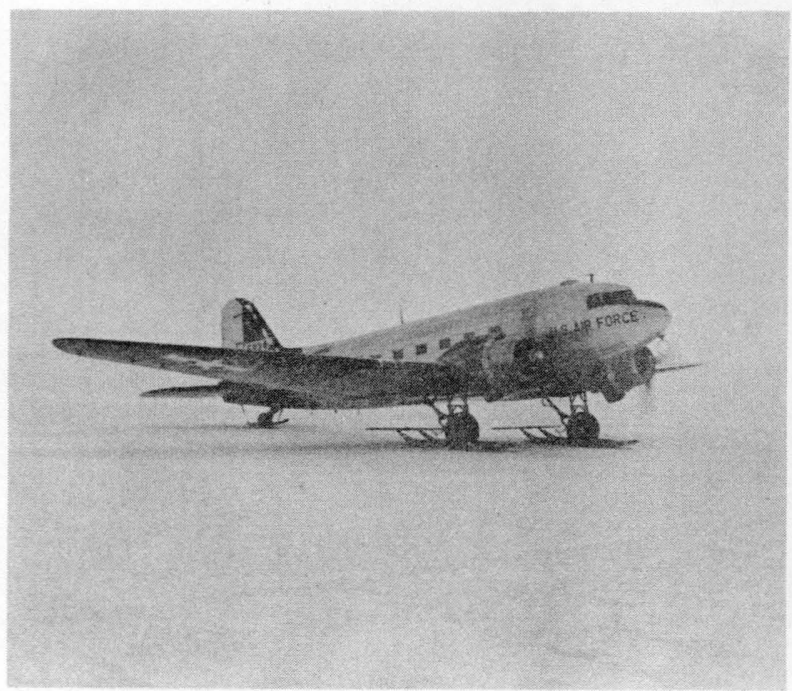

Figure 6. Ski-wheeled C-47 airplane on strip.

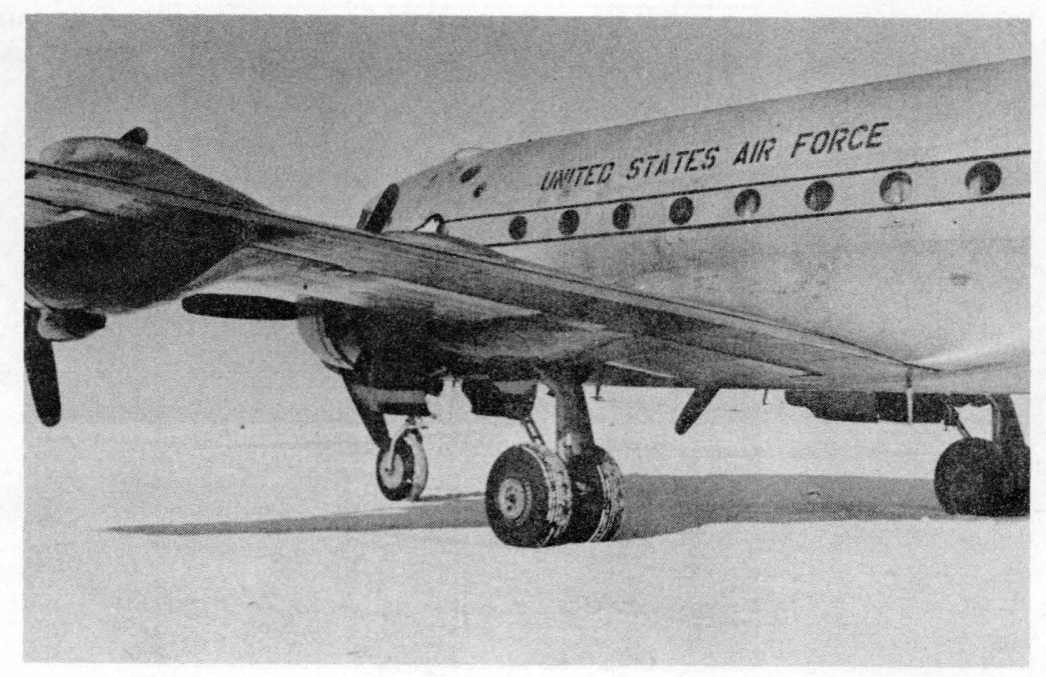

Figure 7. C-54 airplane on strip. 


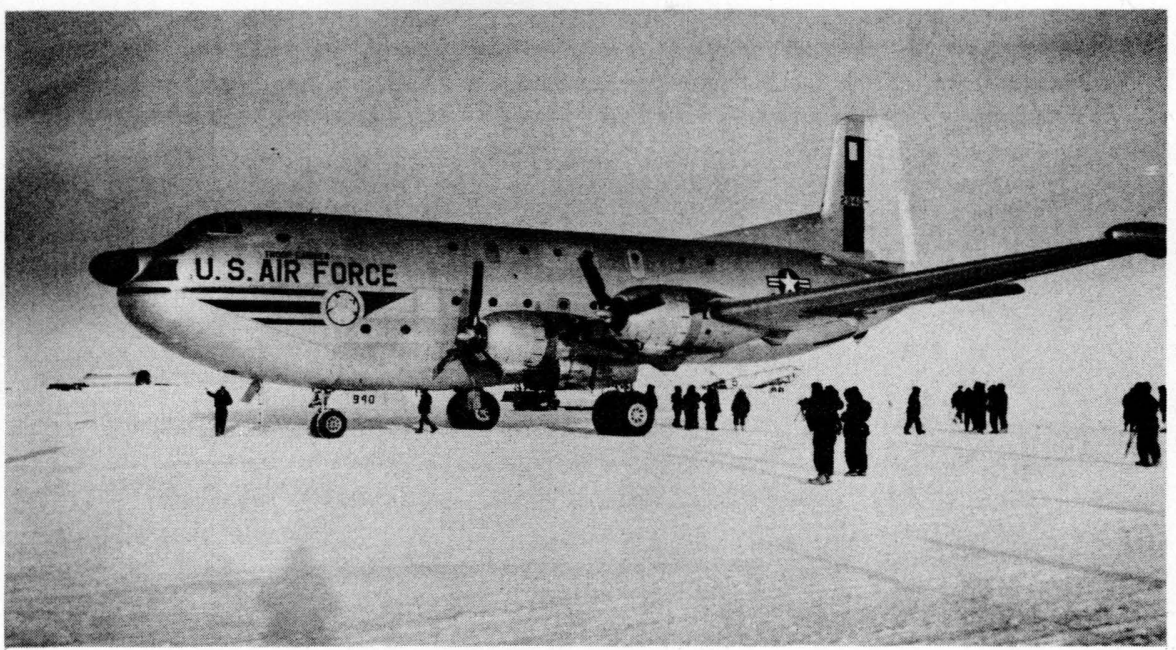

Figure 8. C-124 airplane on strip.

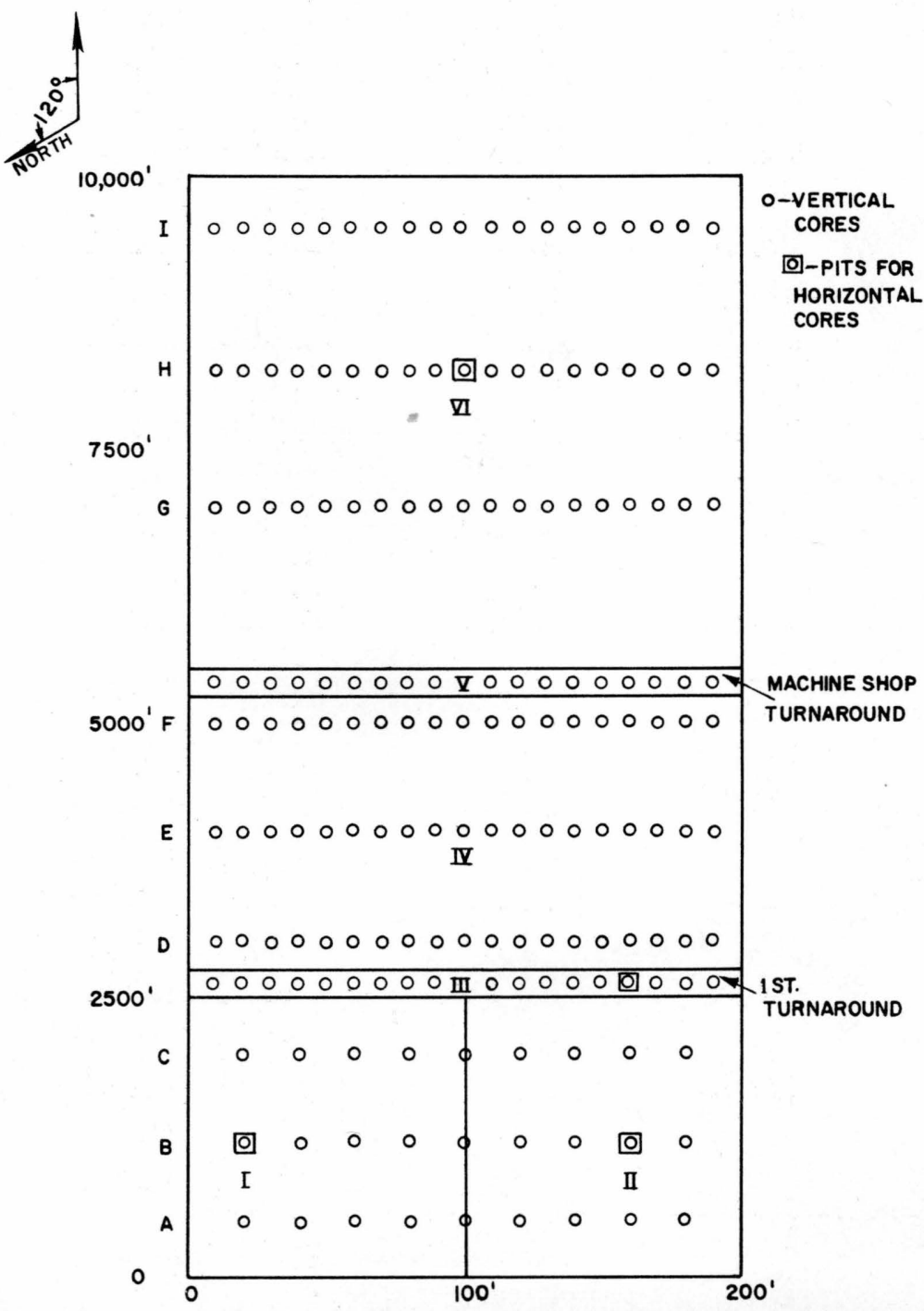

Figure 9. Division of processing of the strip into sections. 


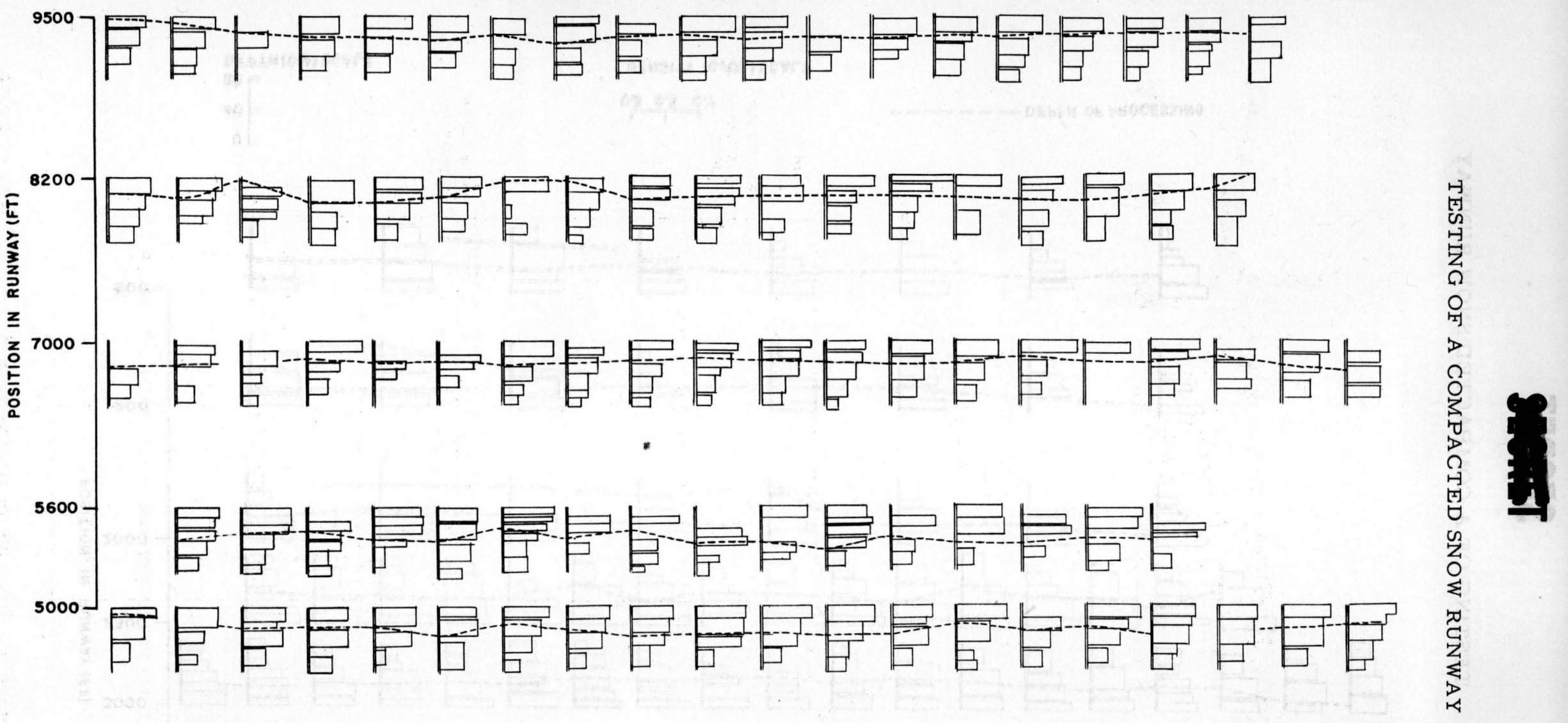




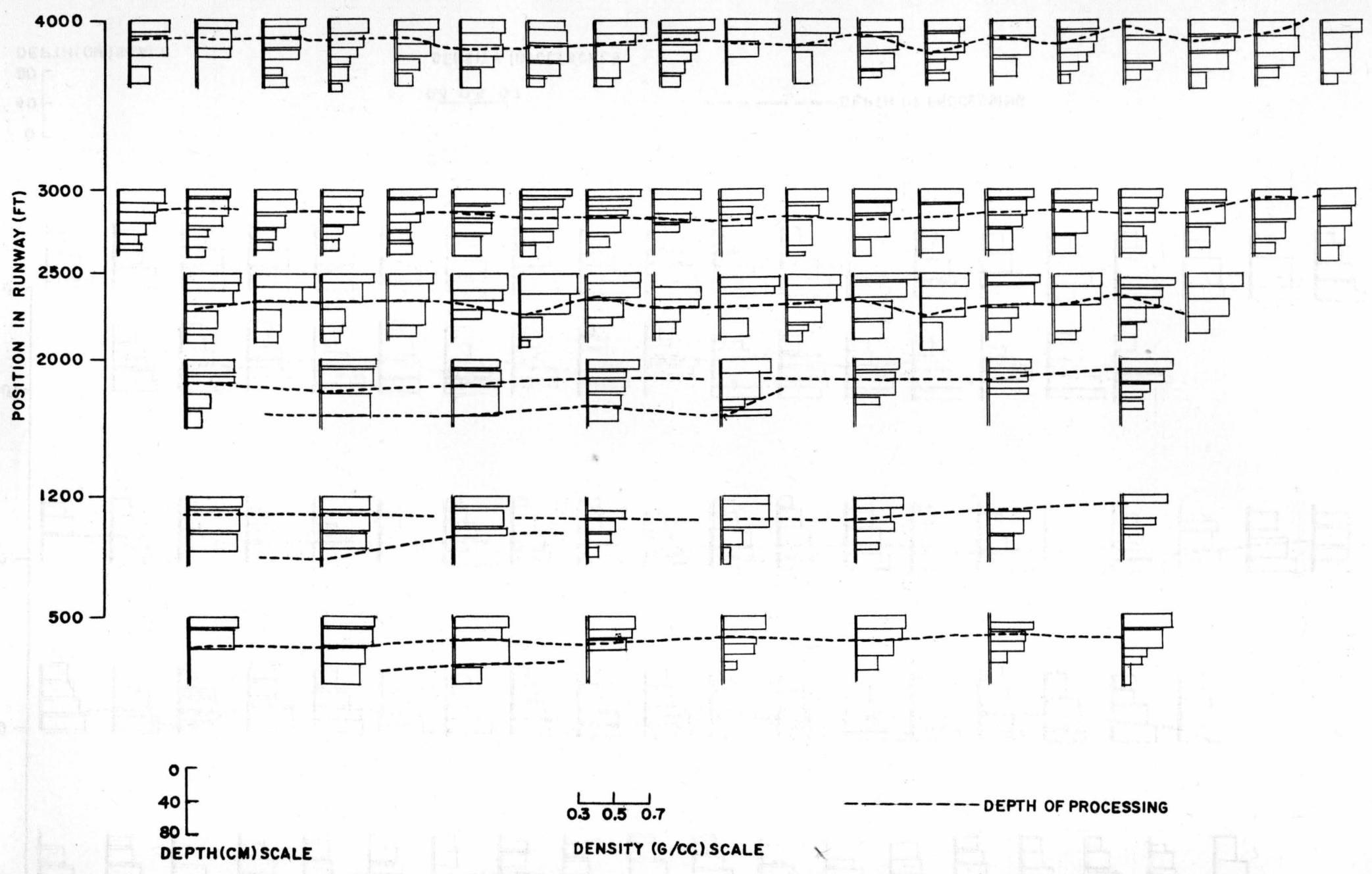



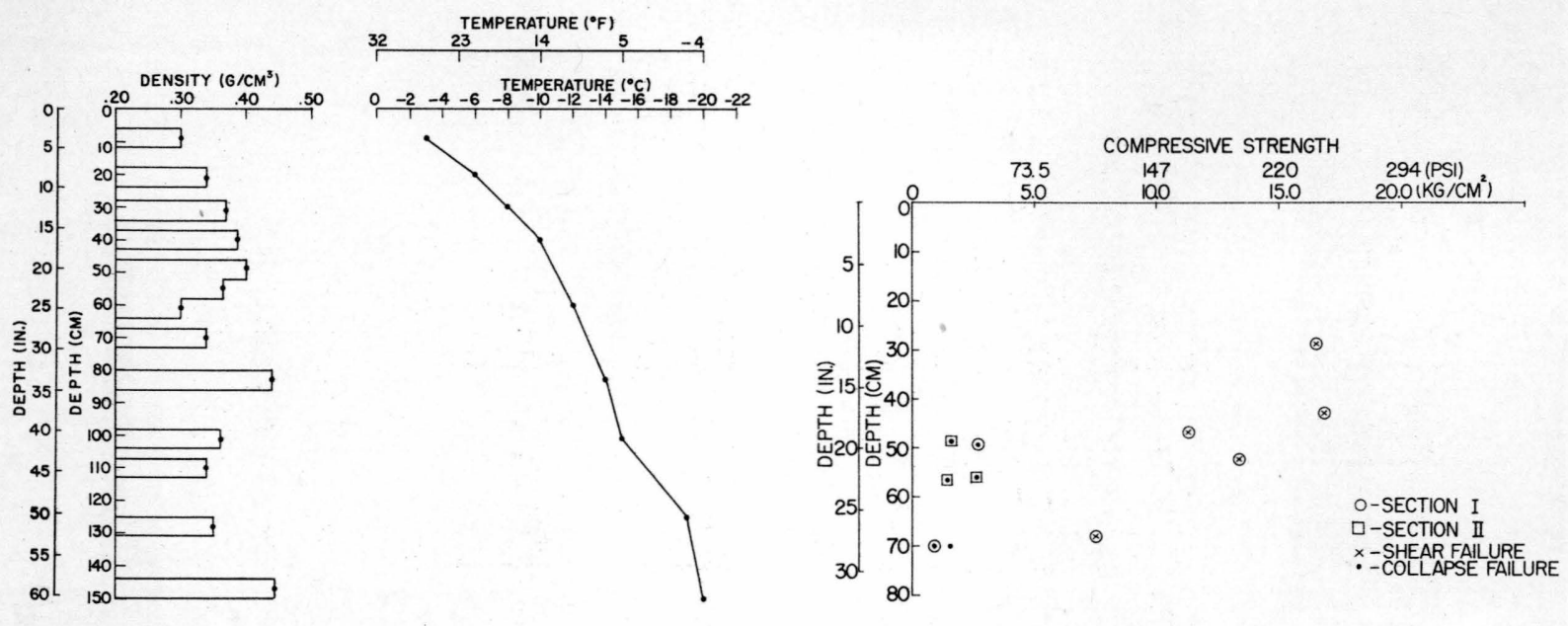

Figure 11. Density and temperature profile of snow before processing.

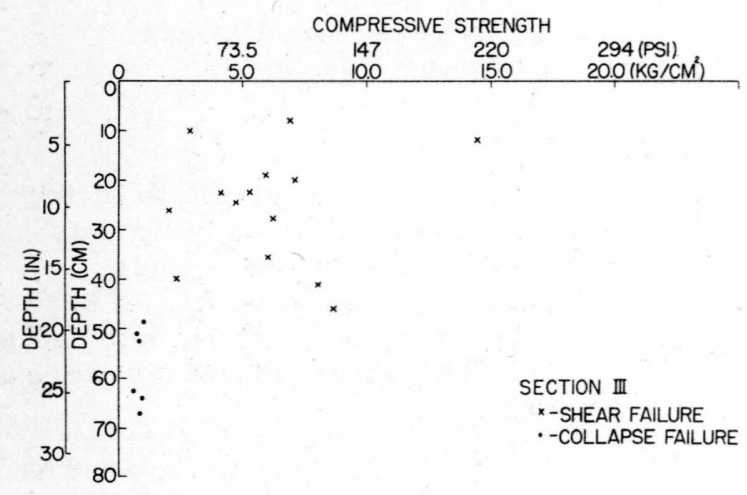

Figure 13. Compressive strength vs. depth, Section III.

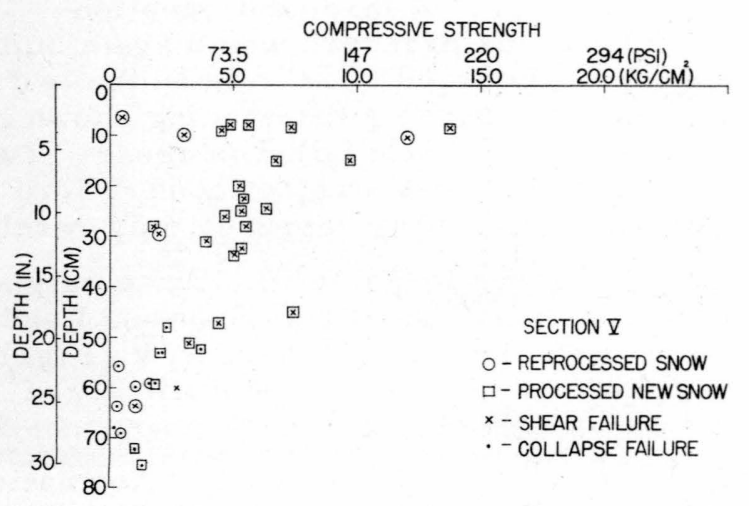

Figure 15. Compressive strength vs. depth, Section V.

Figure 12. Compressive strength vs. depth, sections I and II.

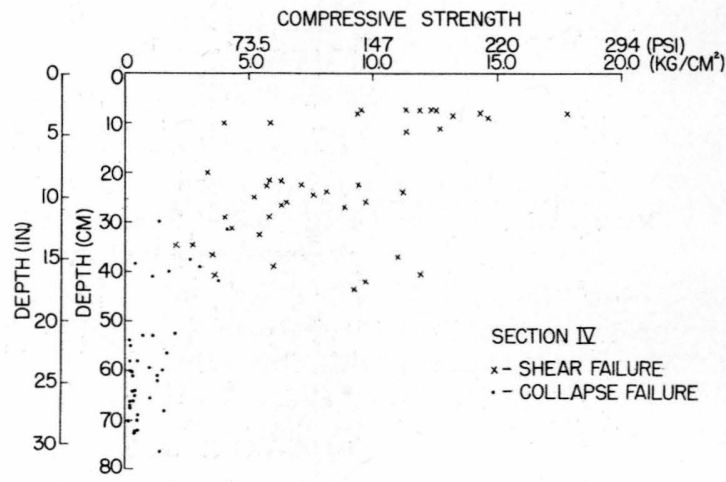

Figure 14. Compressive strength vs. depth, Section IV.

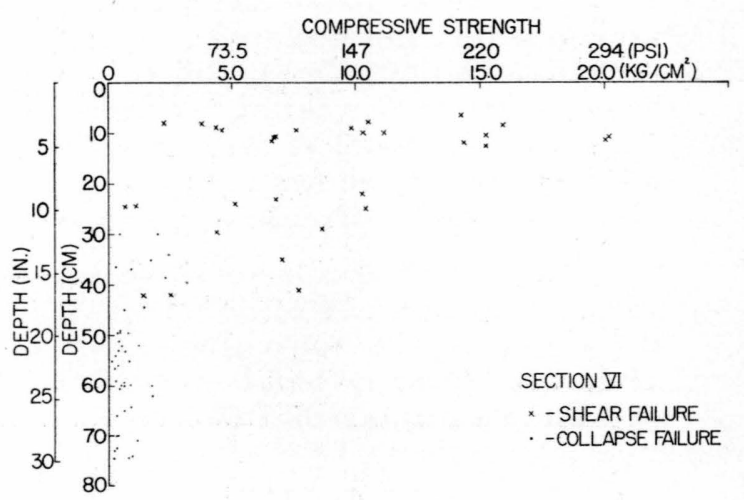

Figure 16. Compressive strength vs. depth, Section VI. 


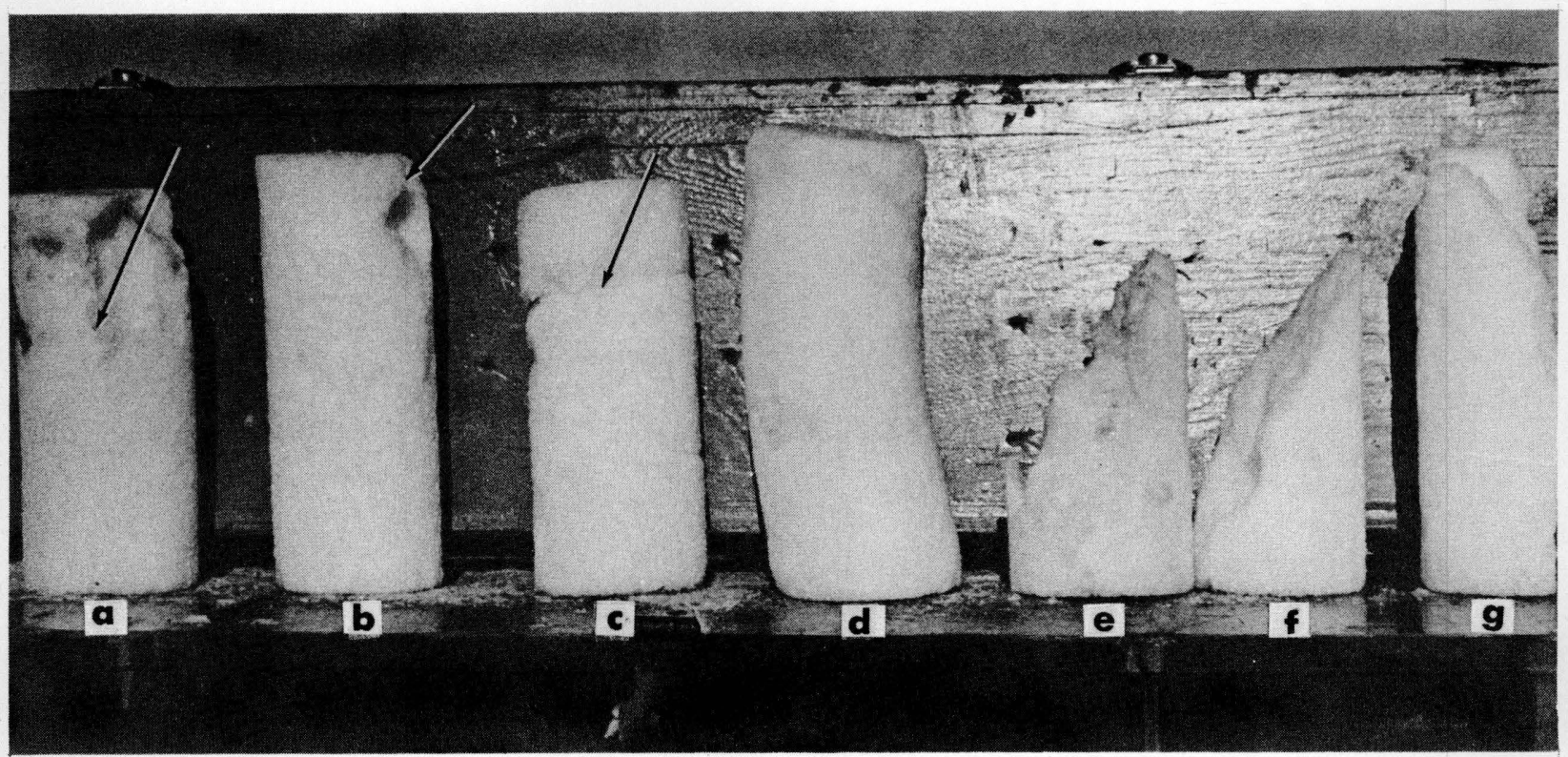

Figure 17. Type of break of specimen under compression. a) Collapse at interface of hard and soft layers. b) Failure at base. c) Collapse. d) Bending. e) Shear. f) Shear. g) Axial break.

Compressive strength. The ultimate unconfined compressive strength of the vertical cores (Fig. 12-16) was determined with the mechanically loaded press (Fig. 4). The cores were allowed to come to the temperature of the testing laboratory; the average rate of loading was about $8.8 \mathrm{~kg} / \mathrm{sec}(19 \mathrm{lb} / \mathrm{sec})$. There was no deliberate attempt to vary the temperature or the rate of loading, but rather to keep them about the same, noting the value of each. The strength values we re all corrected to $-10^{\circ} \mathrm{C}$ in the manner shown in the appendix.

The specimen would break in various ways as shown in Figure 17. Care was taken in cutting core specimens to exclude more than one stratum of snow, as a break similar to the one shown in Figure 17a would result. The second specimen (17b) shows a break at the base which was caused either by an uneven base, or by an inherent weakness in the snow near the base. Almost all of the virgin snow and the lower-density processed snow samples broke by a collapse of the snow structure in a horizontal plane, as shown in Figure 17c. A large deformation accompanied the collapse. If the loading continued, the pressure would again build up and cause another collapse. In a few cases on processed snow, where the two bases were not parallel, eccentric loading developed, causing the bending shown in Figure 17d. Most of the strong specimens of processed snow failed in shear. Two such cases are shown in $17 \mathrm{e}$ and $17 \mathrm{f}$ and another case, not shown, of cone failure also occurred. Breaking along the axis of loading (Fig. 17g) happened only rarely.

The average compressive strength values are given in Table III. Since only a very small number of compressive tests were run on samples from Sections I and II, these values are not included. Also only a few tests we re run on Section V (Fig. 15) after the old snow had been reprocessed, but this was because of the difficulty of obtaining samples that did not crumble.

Stress/strain ratio. The press was so designed that the amount of deformation of the sample as well as the load could be read. Four typical stress-strain curves are shown in Figure 18. The variation of the linear portion of the stress-strain ratios with depth for Sections IV and VI are shown in figures 19 and 20 . The length of the lines indicates the length of the specimen and its position. The averages are shown in Table IV. 


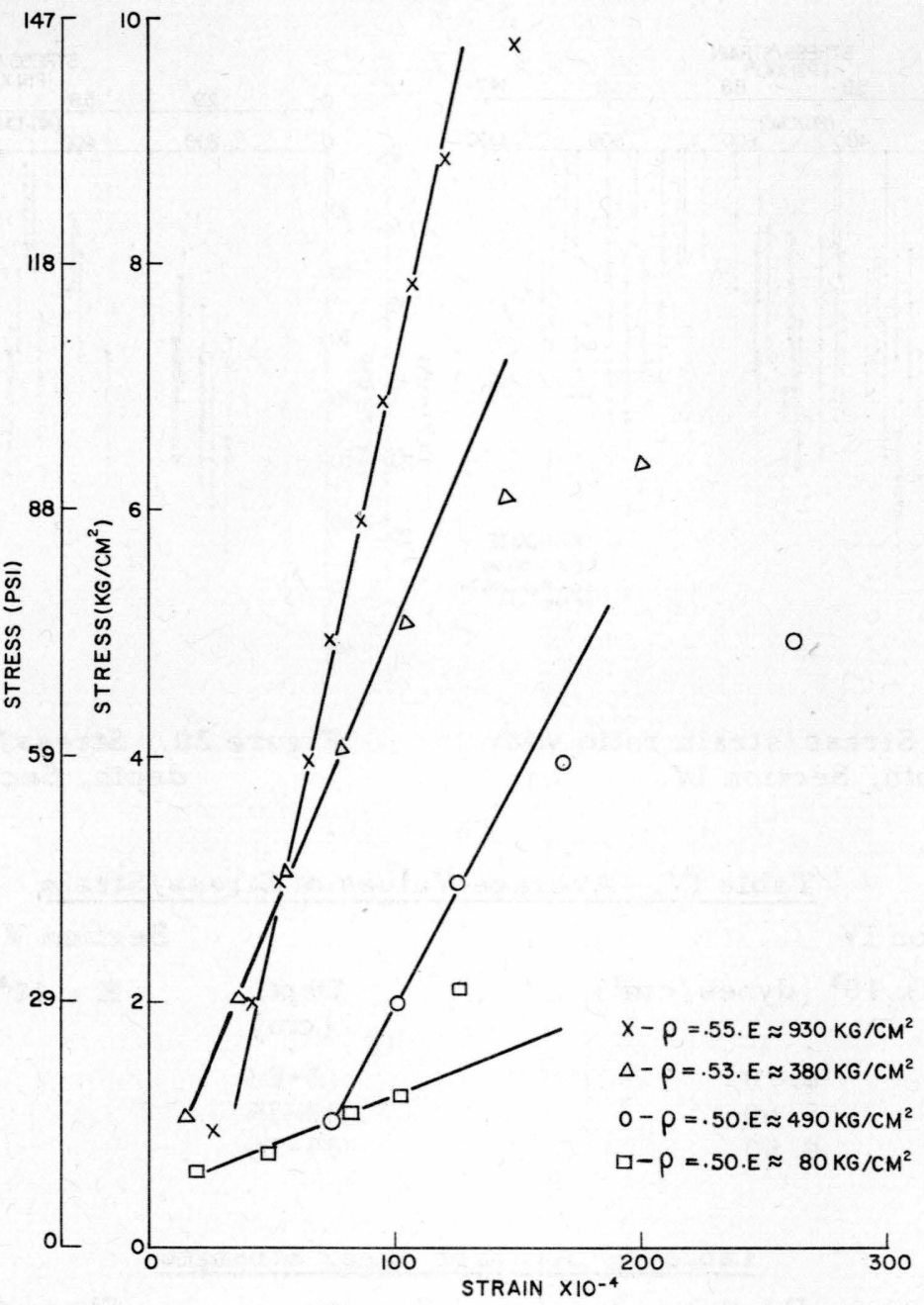

Figure 18. Stress-strain curves for four typical specimens.

Table ШI. Average Compressive Strengths

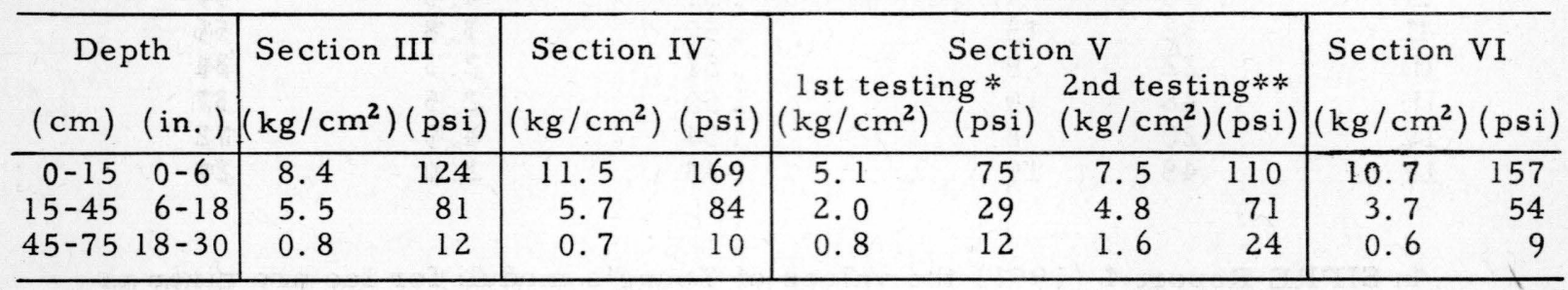

* Old snow reprocessed for the second time.

** Processed virgin snow hauled in. 


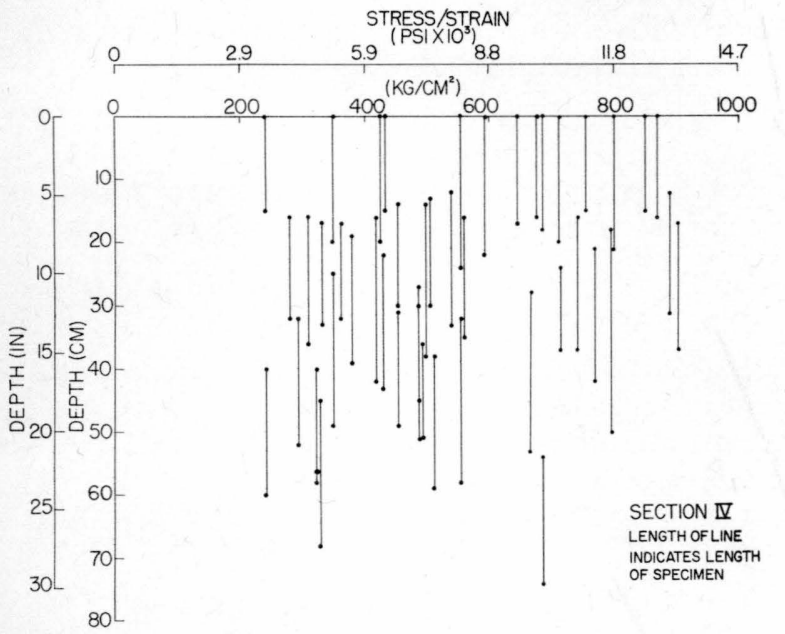

Figure 19. Stress/strain ratio with depth, Section IV.

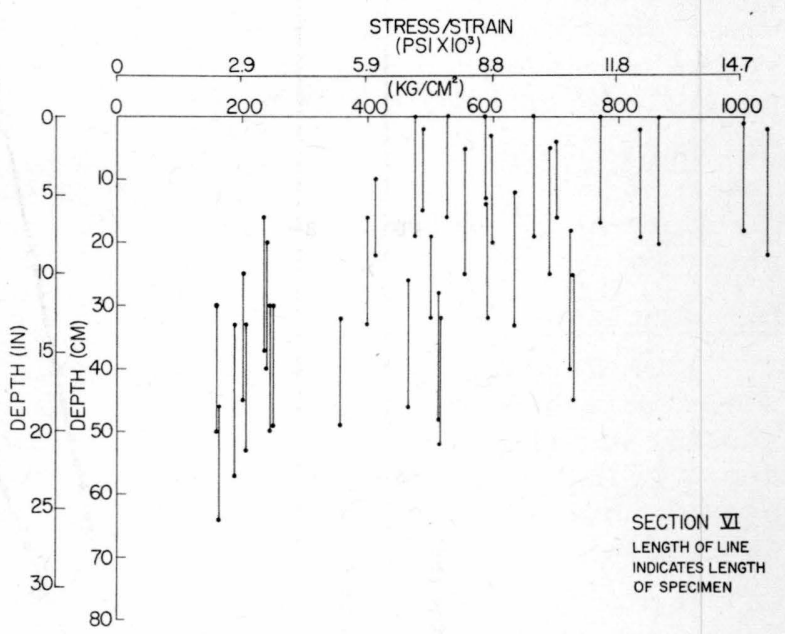

Figure 20. Stress/strain ratio with depth, Section VI.

\section{Table IV. Average Values of Stress/Strain}

\begin{tabular}{|c|c|c|c|}
\hline \multicolumn{2}{|c|}{ Section IV } & \multicolumn{2}{|c|}{ Section V } \\
\hline $\begin{array}{l}\text { Depth } \\
(\mathrm{cm})\end{array}$ & $\mathrm{E} \times 10^{8}\left(\right.$ dynes $\left./ \mathrm{cm}^{2}\right)$ & $\begin{array}{c}\text { Depth } \\
(\mathrm{cm})\end{array}$ & $\mathrm{E} \times 10^{8}\left(\right.$ dynes $\left./ \mathrm{cm}^{2}\right)$ \\
\hline $\begin{array}{r}0-15 \\
15-33 \\
33-70\end{array}$ & $\begin{array}{l}6.10 \\
5.60 \\
4.50\end{array}$ & $\begin{array}{r}0-20 \\
20-35 \\
35-70\end{array}$ & $\begin{array}{l}6.60 \\
4.80 \\
3.10\end{array}$ \\
\hline
\end{tabular}

Table V. Average Shear Strength

\begin{tabular}{|c|c|c|c|c|c|}
\hline \multirow[t]{2}{*}{ Section } & \multicolumn{2}{|c|}{ Depth } & \multirow{2}{*}{$\begin{array}{l}\text { Density } \\
\left(\mathrm{g} / \mathrm{cm}^{3}\right)\end{array}$} & \multicolumn{2}{|c|}{ Shear Strength } \\
\hline & $(\mathrm{cm})$ & (in.) & & $\left(\mathrm{kg} / \mathrm{cm}^{2}\right)$ & (psi) \\
\hline I & 17 & 7 & .61 & 4.2 & 62 \\
\hline I & 43 & 17 & .57 & 3.1 & 46 \\
\hline I & 87 & 35 & .53 & 3.3 & 49 \\
\hline II & 10 & 4 & .57 & 4.0 & 59 \\
\hline II & 32 & 13 & .50 & 3.8 & 56 \\
\hline III & 22 & 9 & .57 & 2.3 & 34 \\
\hline III & 48 & 19 & .50 & 2.5 & 37 \\
\hline IV & 20 & 8 & .54 & 4.9 & 72 \\
\hline IV & 48 & 19 & 48 & 2. 0 & 29 \\
\hline
\end{tabular}

In SIPRE Report 4 (1951) the values of Young's moduli for ice are given as 1 to $5 \times 10^{10}$ dynes $/ \mathrm{cm}^{2}$ for static tests and about $10 \times 10^{10}$ for dynamic tests. Dynarnic tests by Yamaji and Kuroiwa (1954) on 0.54 density snow showed values of about $6 \times 10^{9}$ dynes $/ \mathrm{cm}^{2}$. Landauer (1955) calculated from relaxation data a value of $1.6 \times 10^{9}$ dynes $/ \mathrm{cm}^{2}$ for a snow of 0.42 density. 
It was to be expected that the values obtained from the strip testing would be smaller than those obtained by dynamic means, especially. since we have a visco-elastic porous material. There is certainly some question as to whether values obtained from the stress-strain curves on a material like snow may properly be called Young's moduli.

Shear strength. The shear strength of the snow at zero lateral pressure was determined also with the press. The rates of loading and temperatures we re about the same as for the determination of the compressive strength. The average of ten shear values for each laye $r$ is shown in Table V.

In-place tests

Ram hardness readings were taken at various times on the strip near the places where cores were obtained. The hardness readings for Sections I and II (Figs. 21 and 22) each represent the average of 6 determinations; the ones for Section III and $\mathrm{V}$ (Figs. 23 and 25) each represent the average of 4 determinations; and the ones for Sections IV and VI (Figs. 24 and 26) are each the average of 12 determinations.

It may be noted on all of the graphs that the $0-10 \mathrm{~cm}(0-4 \mathrm{in}$. ) readings are considerably lowe $r$ than the $10-15 \mathrm{~cm}(4-6$ in. ) readings, all in the same hard upper layer. This difference may be explained when it is realized that the Rammsonde is a cone penetrometer and the initial readings will be low until the full diameter of the cone is in the snow. The averaged readings from $0-10 \mathrm{~cm}$ are plotted against the averaged reading from 10-15 cm in Figure 27. In Figures 28-33, showing the average ram number of each layer, the values for $0-10 \mathrm{~cm}$ were replaced by the values of the $10-15 \mathrm{~cm}$ readings. The slope of the straight line in Figure 27 is $\frac{1}{3}$, and since in many cases the surface layer is too shallow to permit readings from $10-15 \mathrm{~cm}$, it is recommended that the $0-10 \mathrm{~cm}$ Rammsonde readings be multiplied by 3 to give more realistic values.

There is a considerable time lag before the ambient temperature changes the s now temperature below the surface. There is also a decrease in amplitude of temperature variation with depth. As the actual temperature of the snow affects its strength (this is explained quantitatively in the appendix), pits in the strip were dug and the temperature with depth obtained at various times.

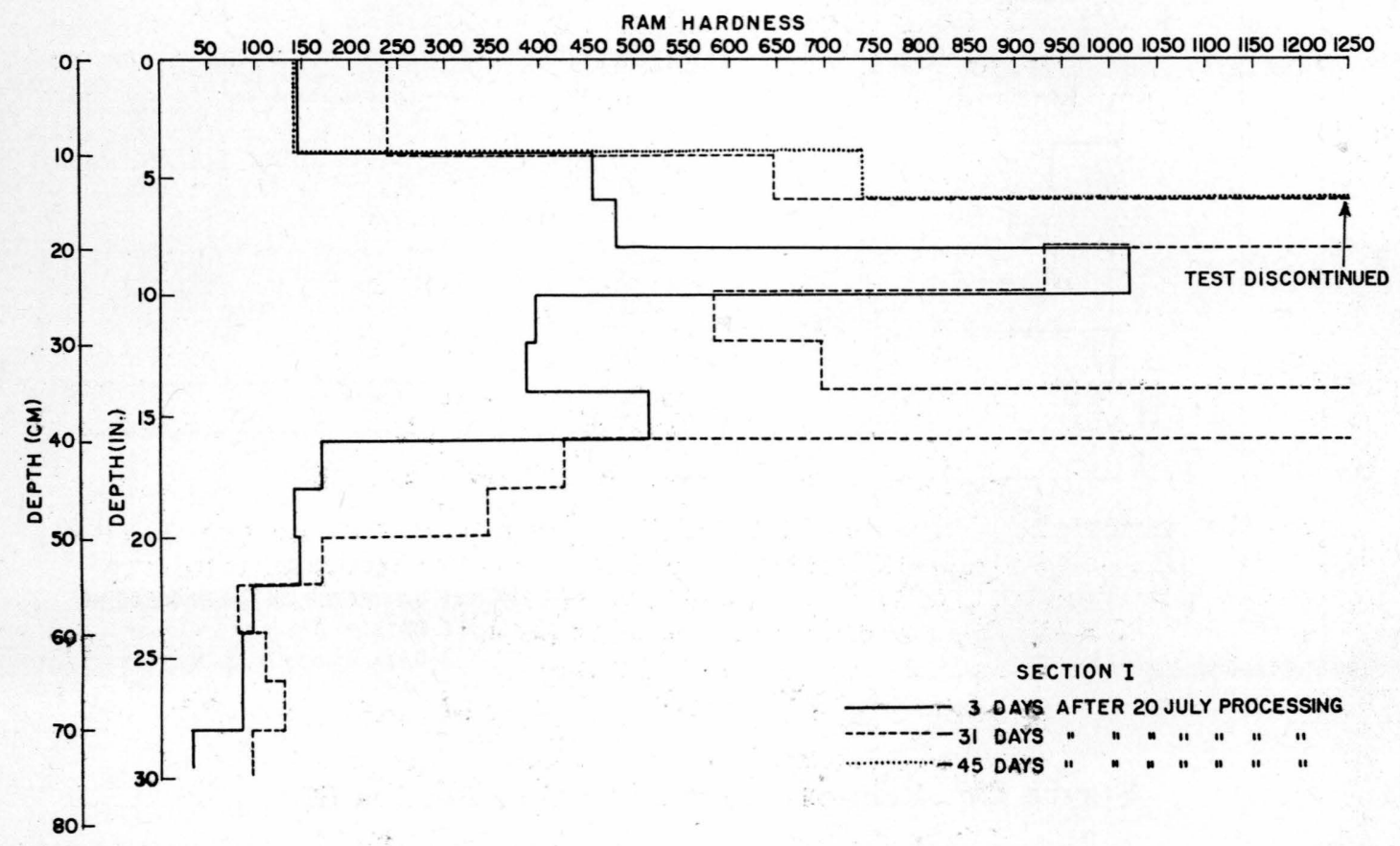

Figure 21. Ram hardness v8. depth, Section I. 


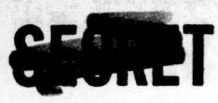

TESTING OF A COMPACTED SNOW RUNWAY

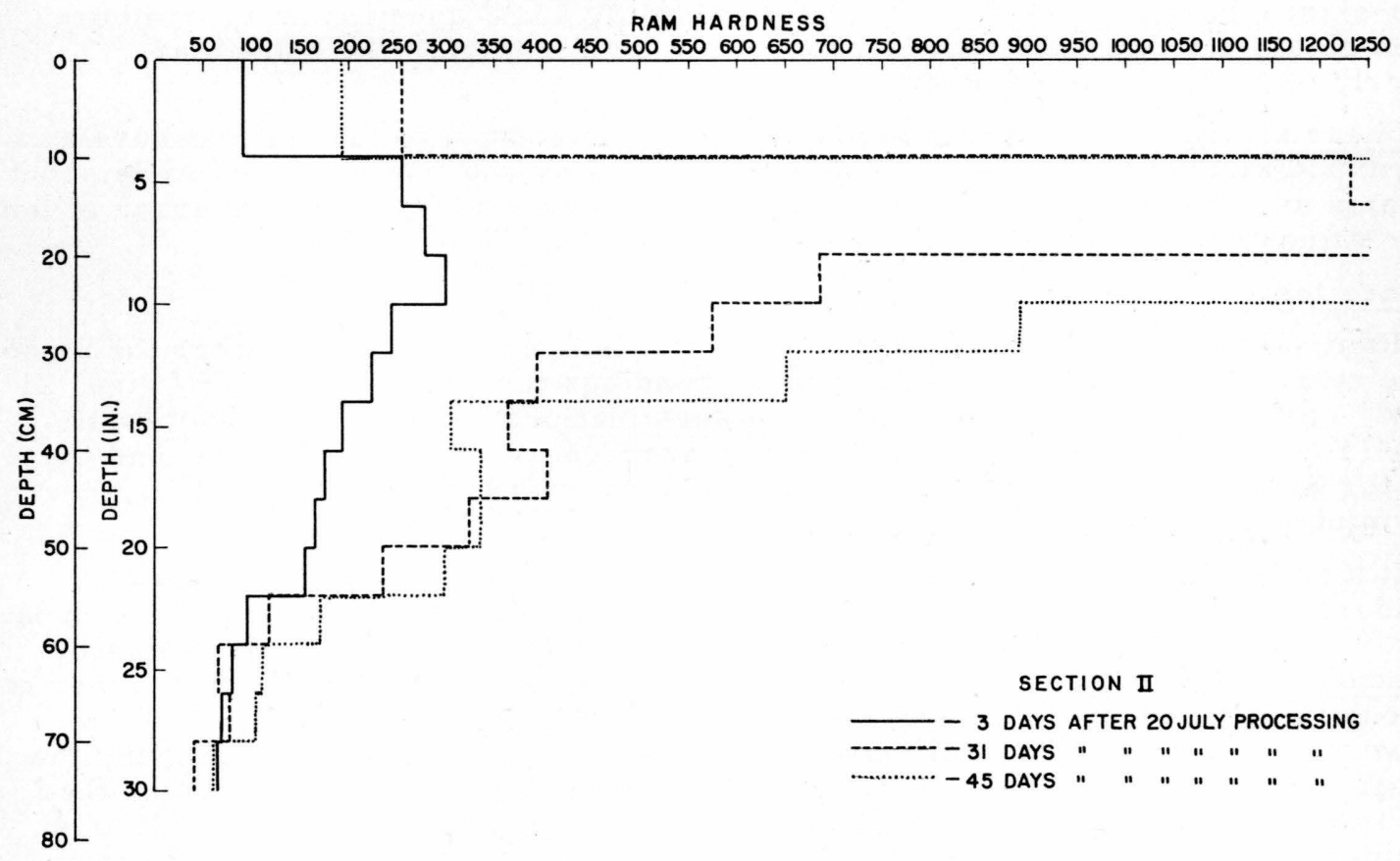

Figure 22. Ram hardness vs. depth, Section II.

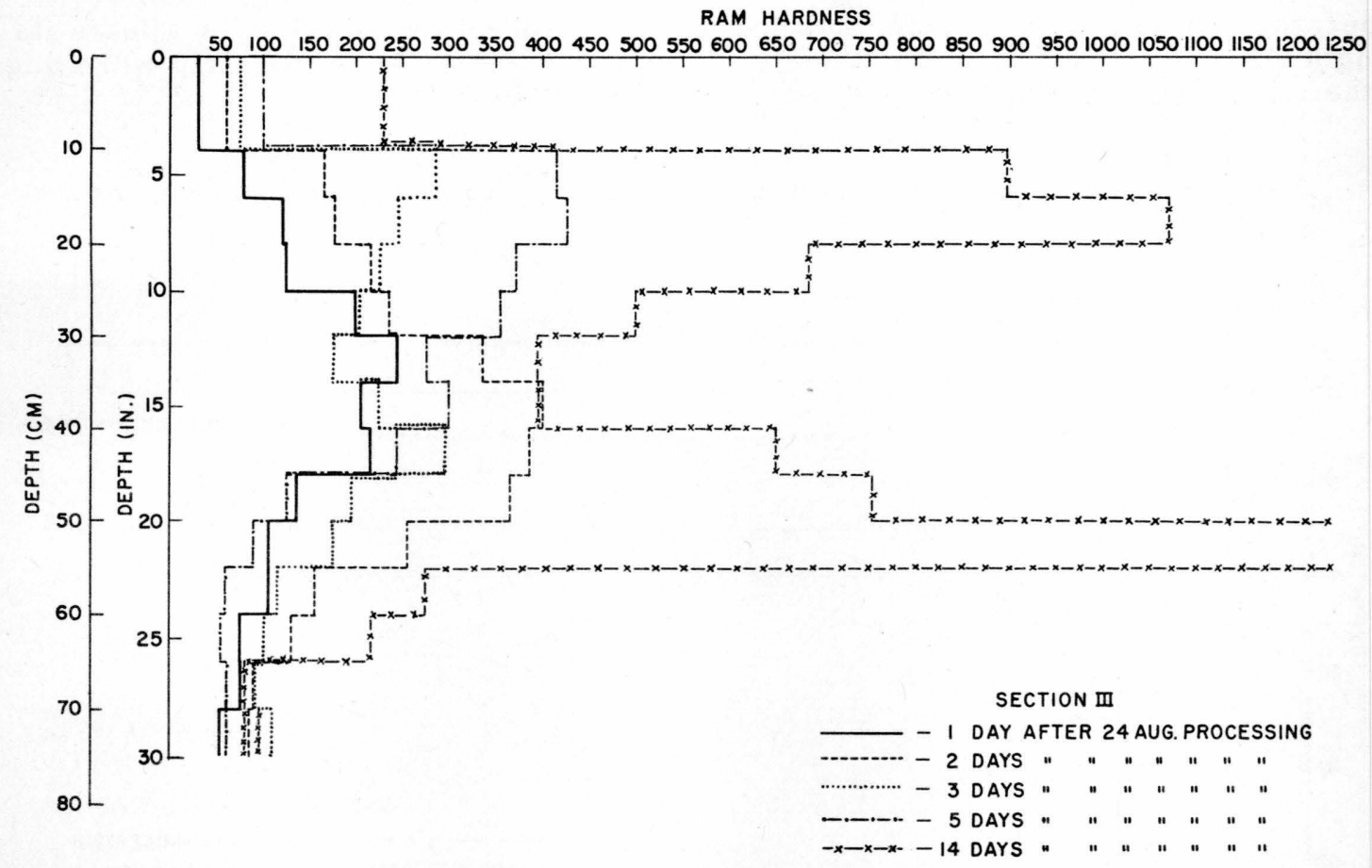

Figure 23. Ram hardness vs. depth, Section III. 


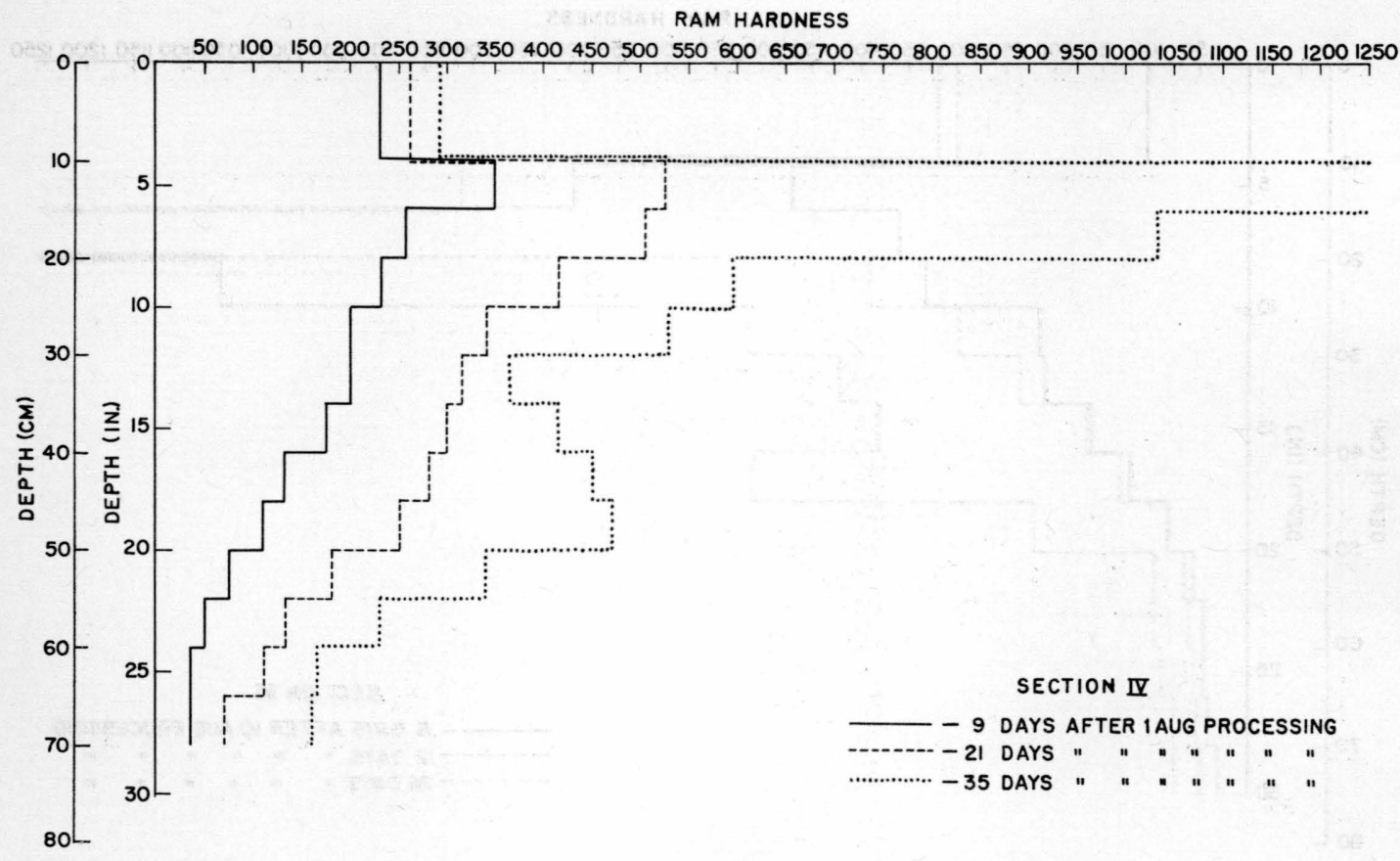

Figure 24. Ram hardness vs, depth, Section IV.

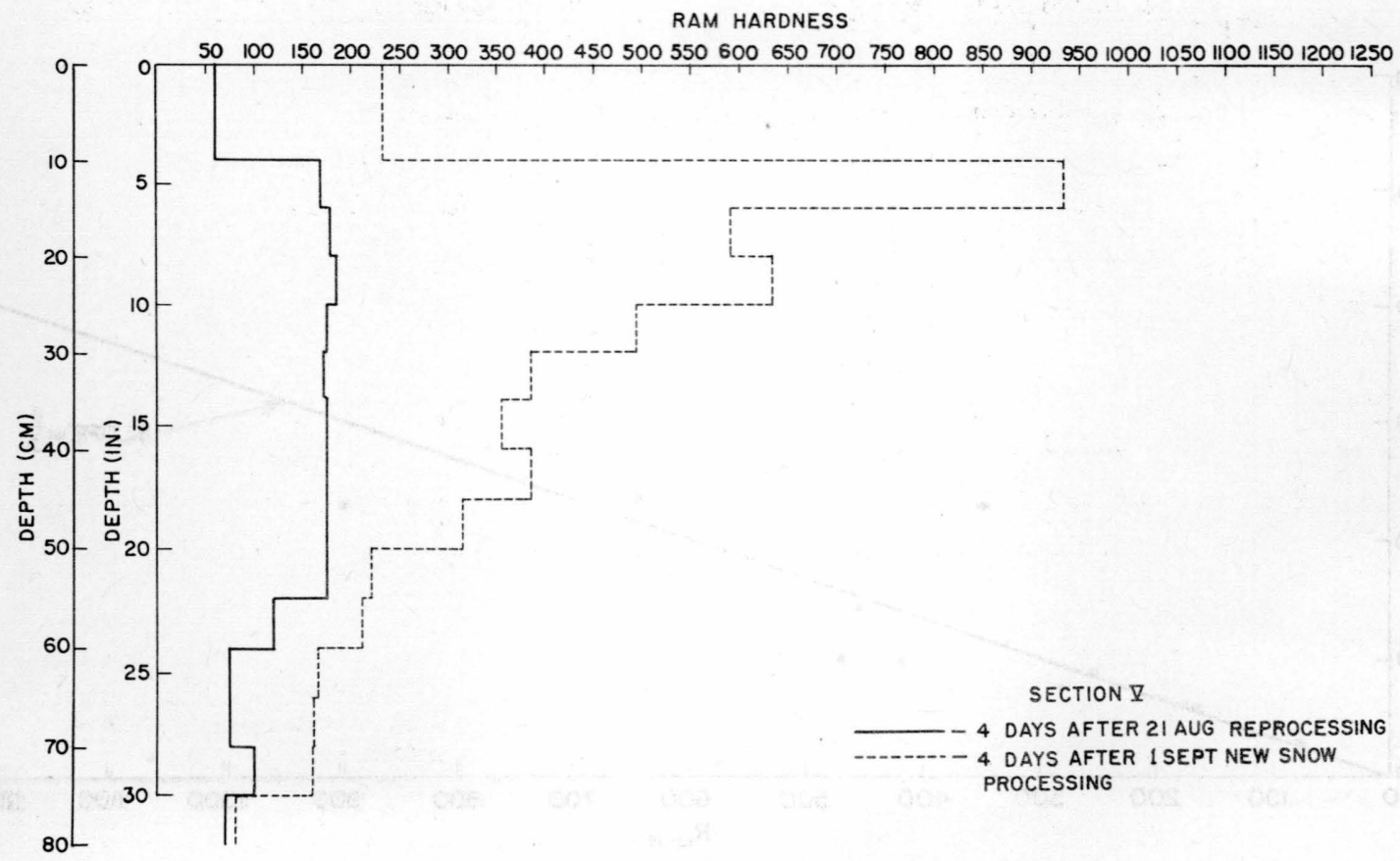

Figure 25. Ram hardness vs. depth, Section V.

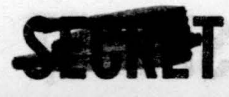



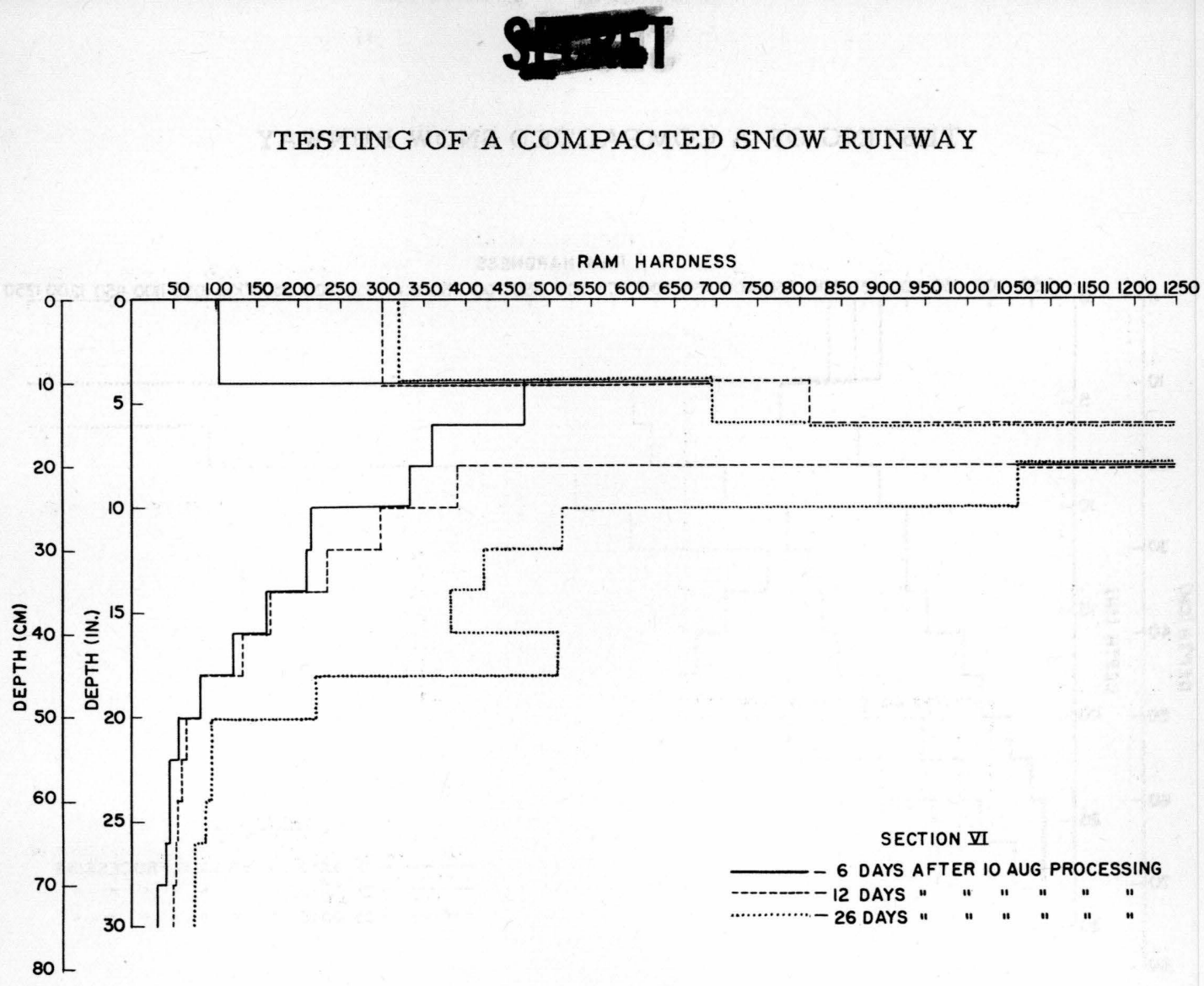

Figure 26. Ram hardness vs. depth, Section VI.

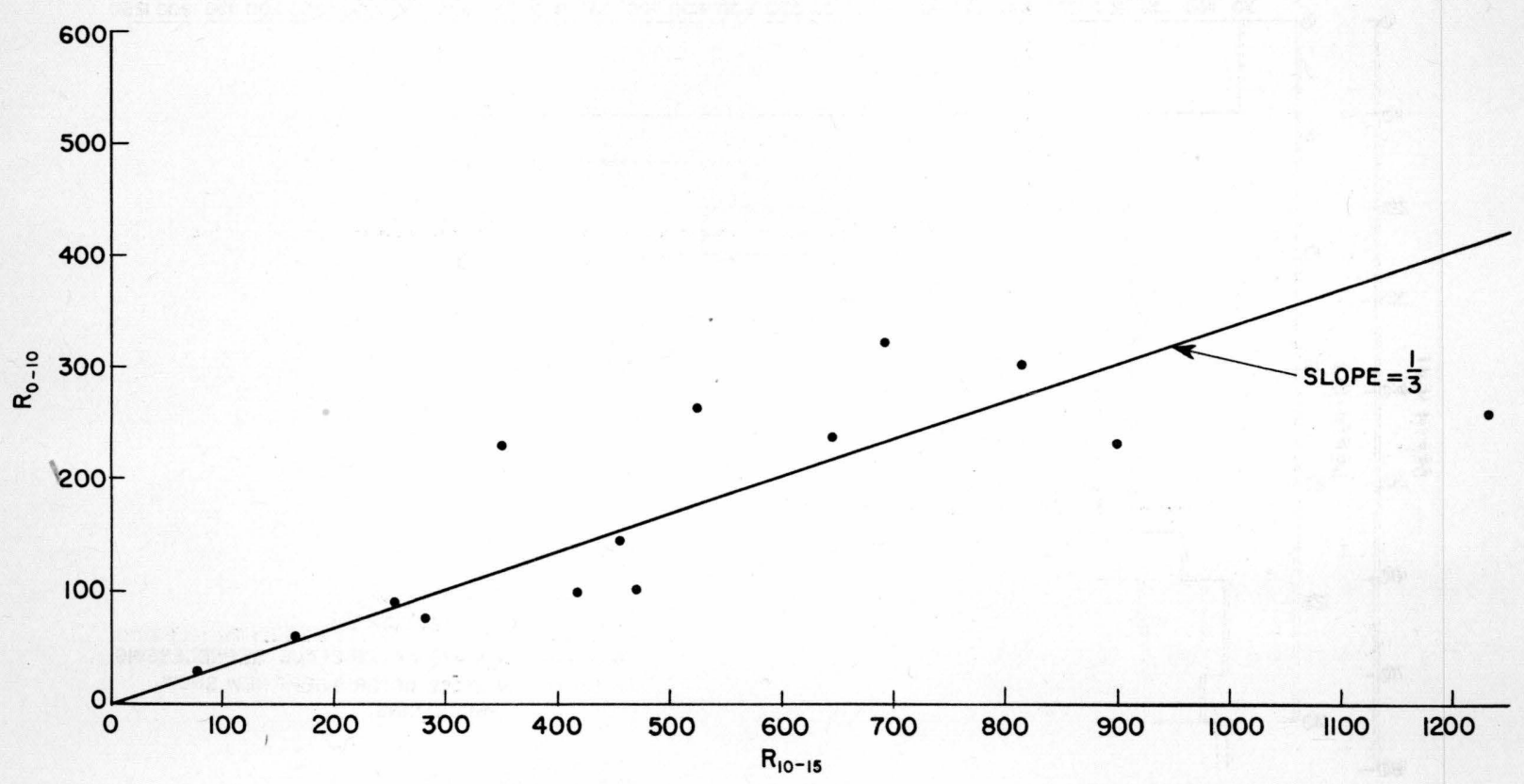

Figure 27. Ram hardness from $0-10 \mathrm{~cm}$ depth vs. $10-15 \mathrm{~cm}$ depth. 


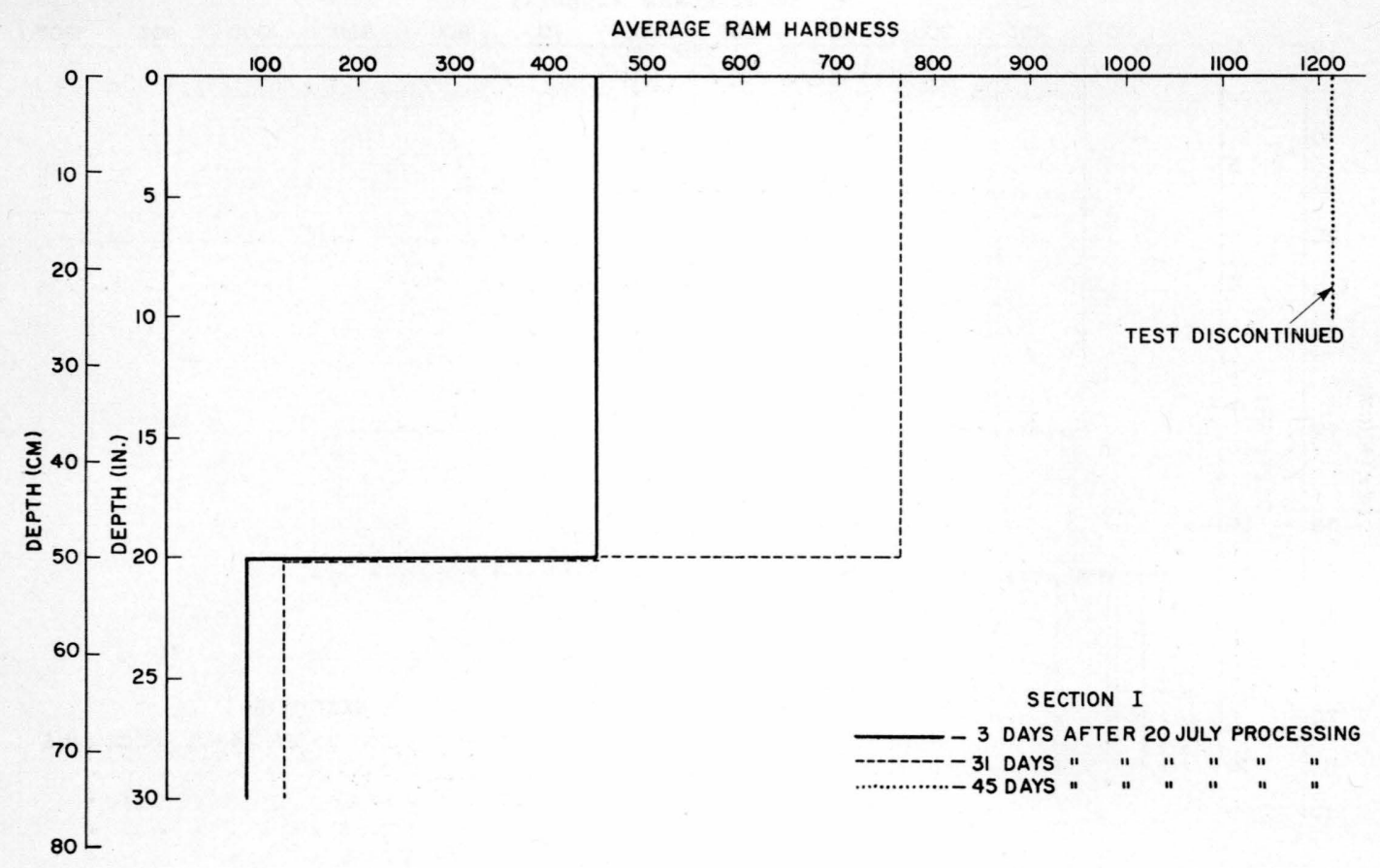

Figure 28. Average ram hardness by layer, Section I.

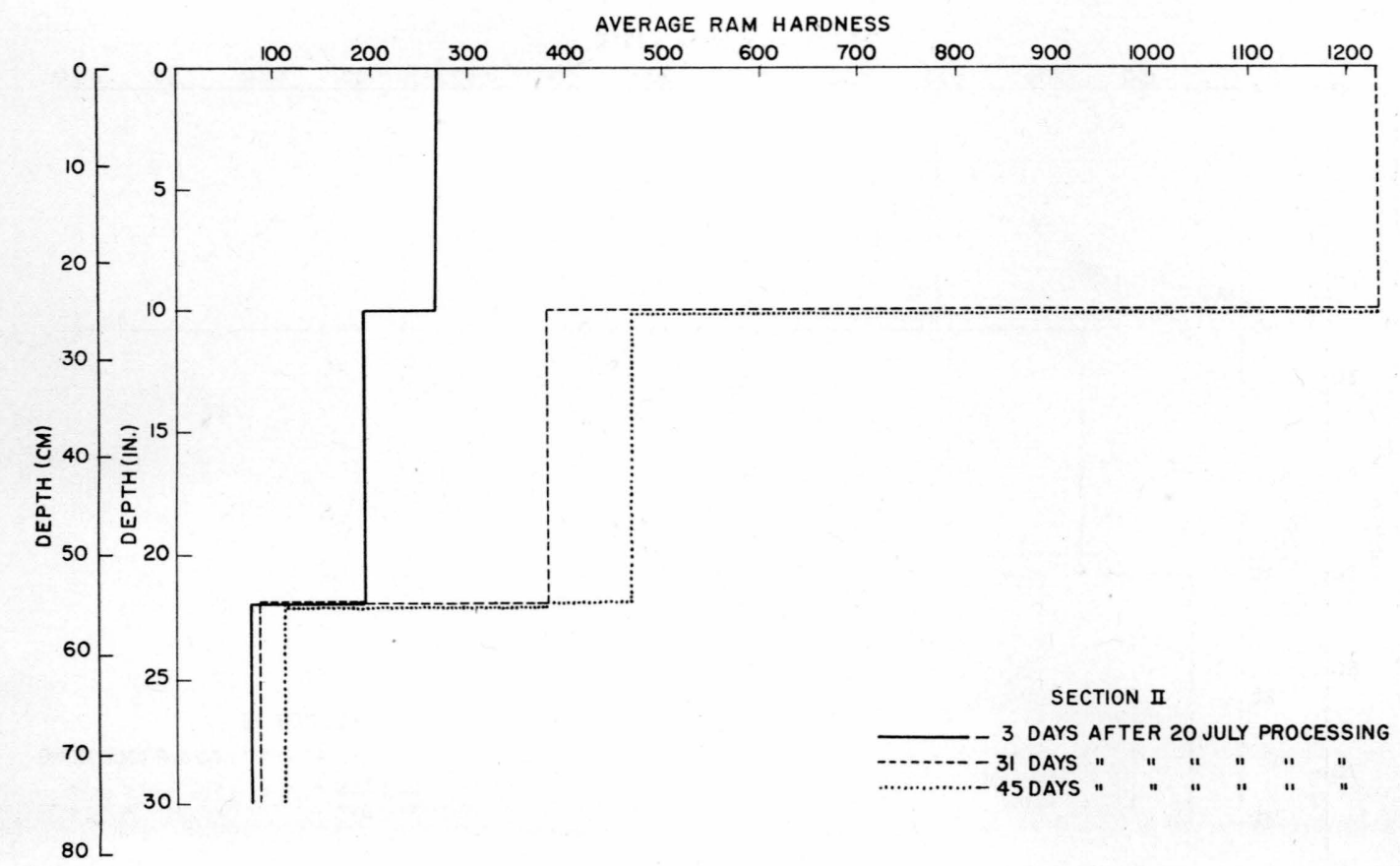

Figure 29. Average ram hardness by layer, Section II. 


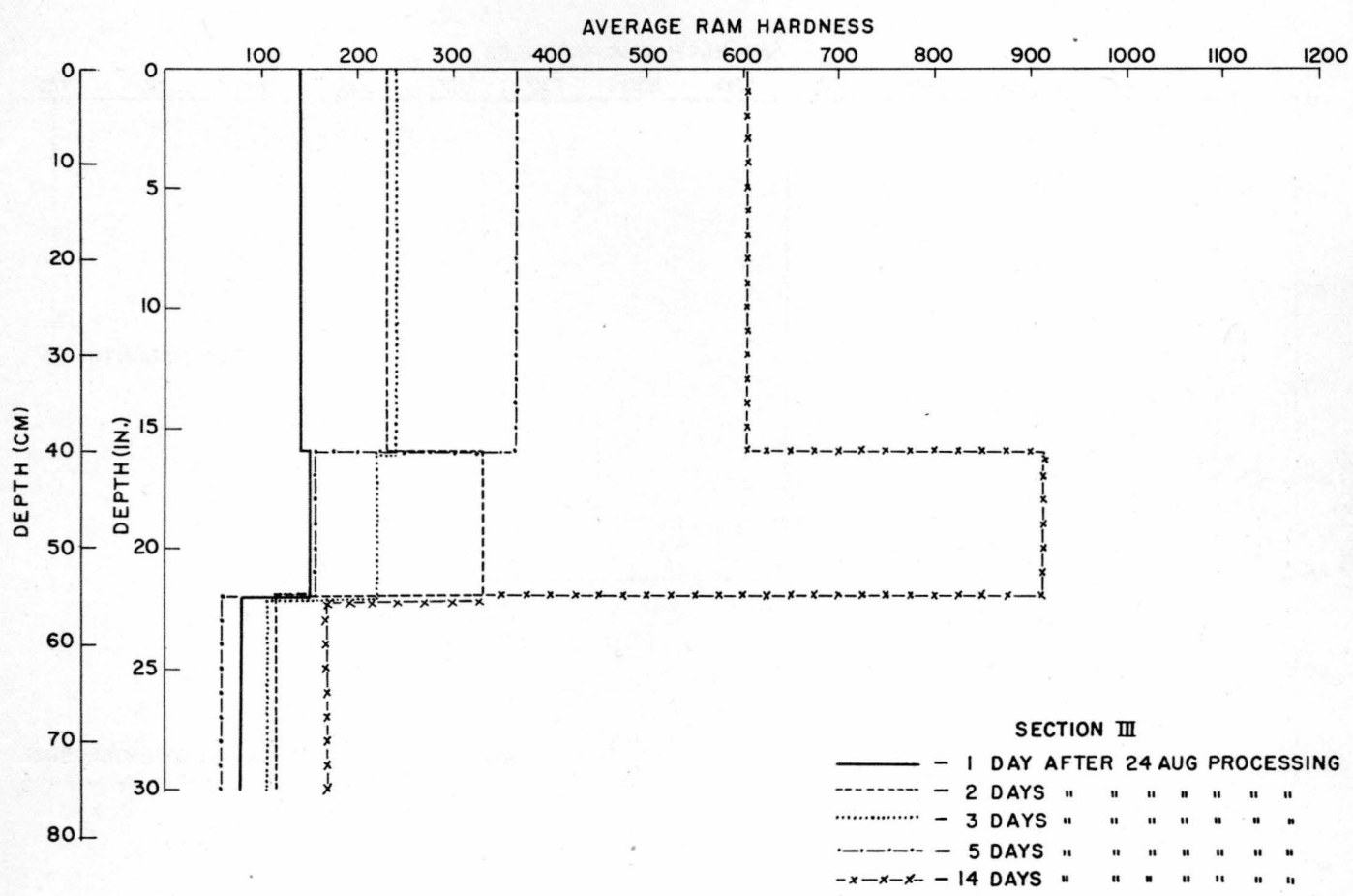

Figure 30. Average ram hardness by layer, Section III.

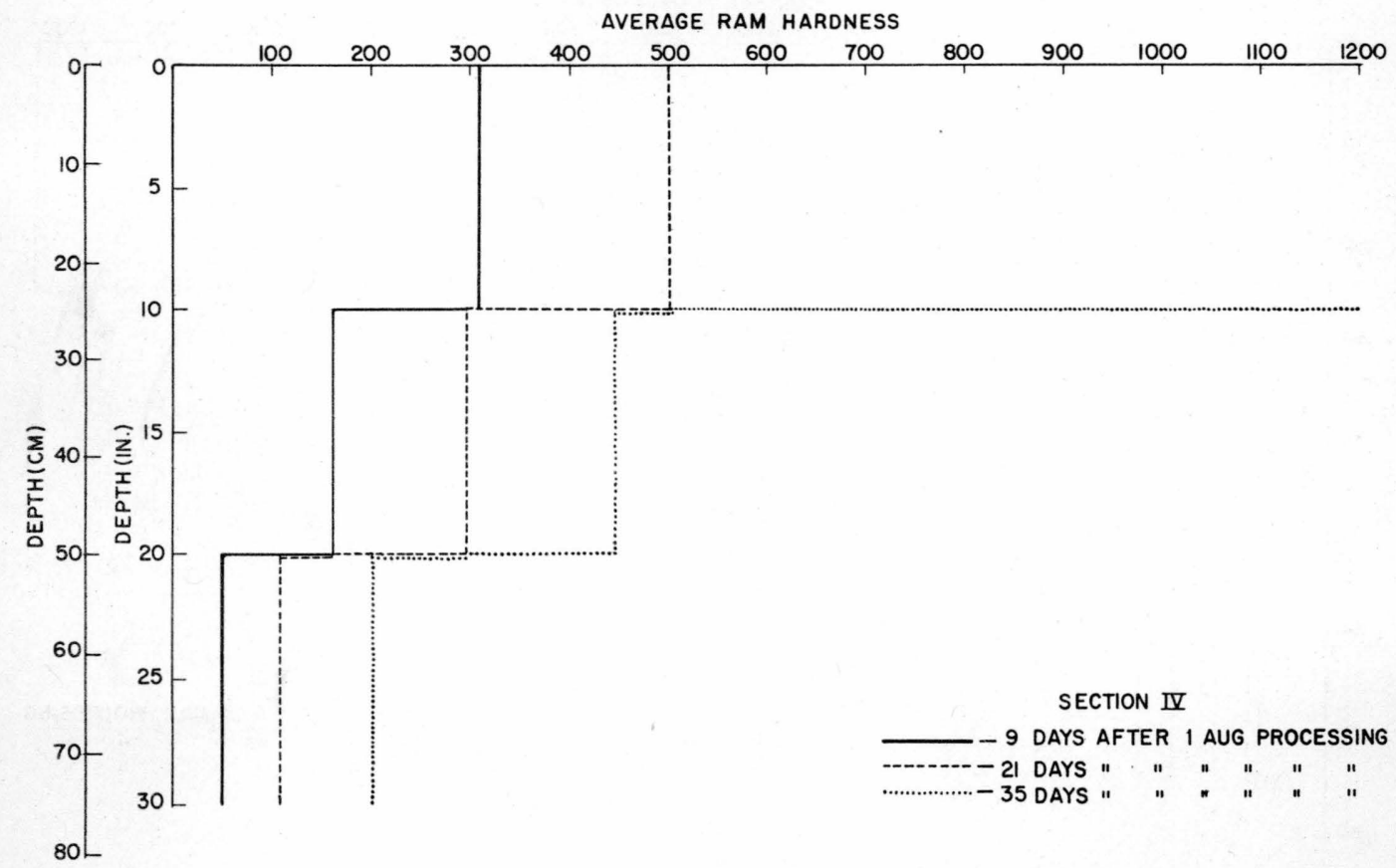

Figure 31. Average ram hardness by layer, Section IV. 


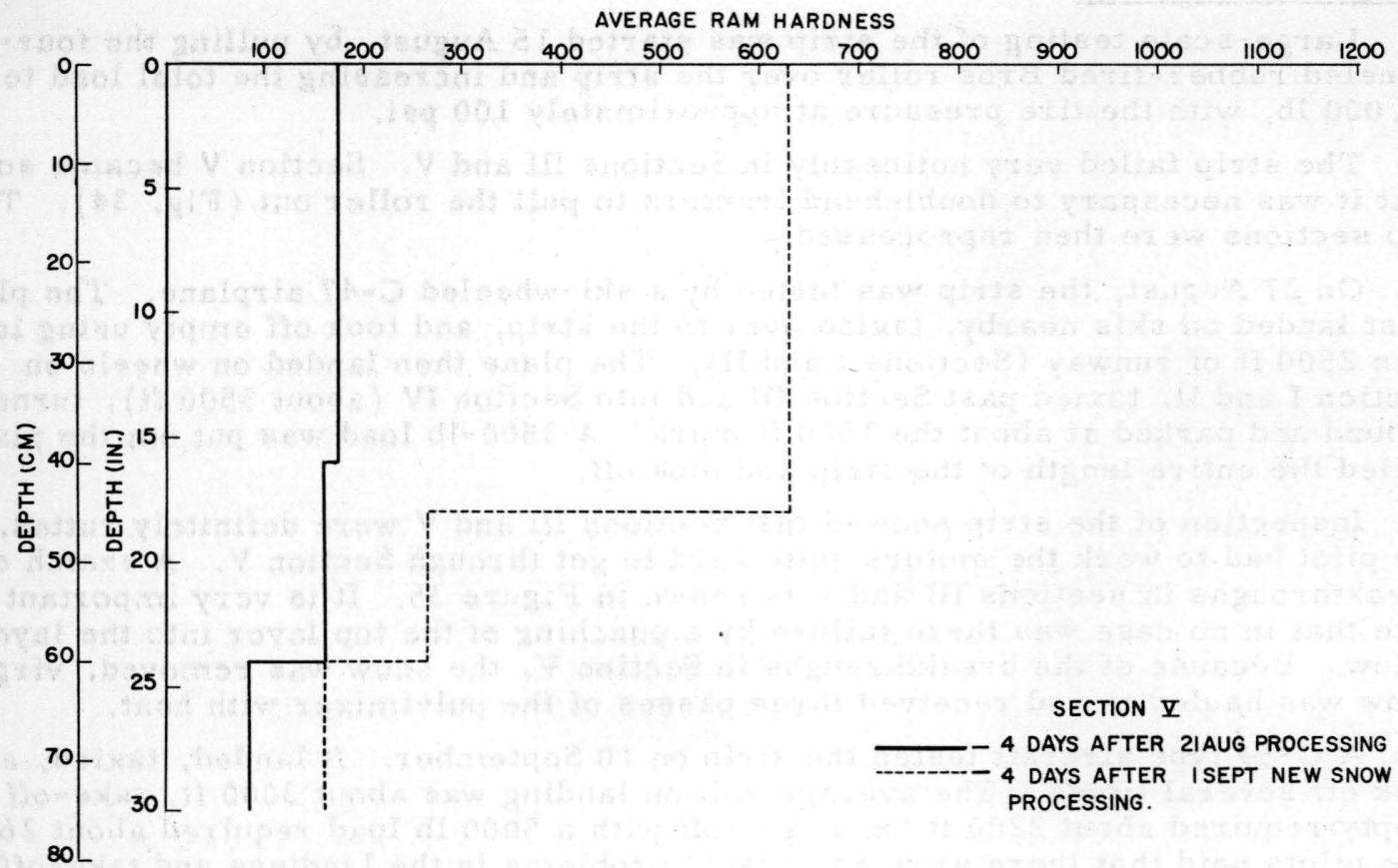

Figure 32. Average ram hardness by layer, Section V.

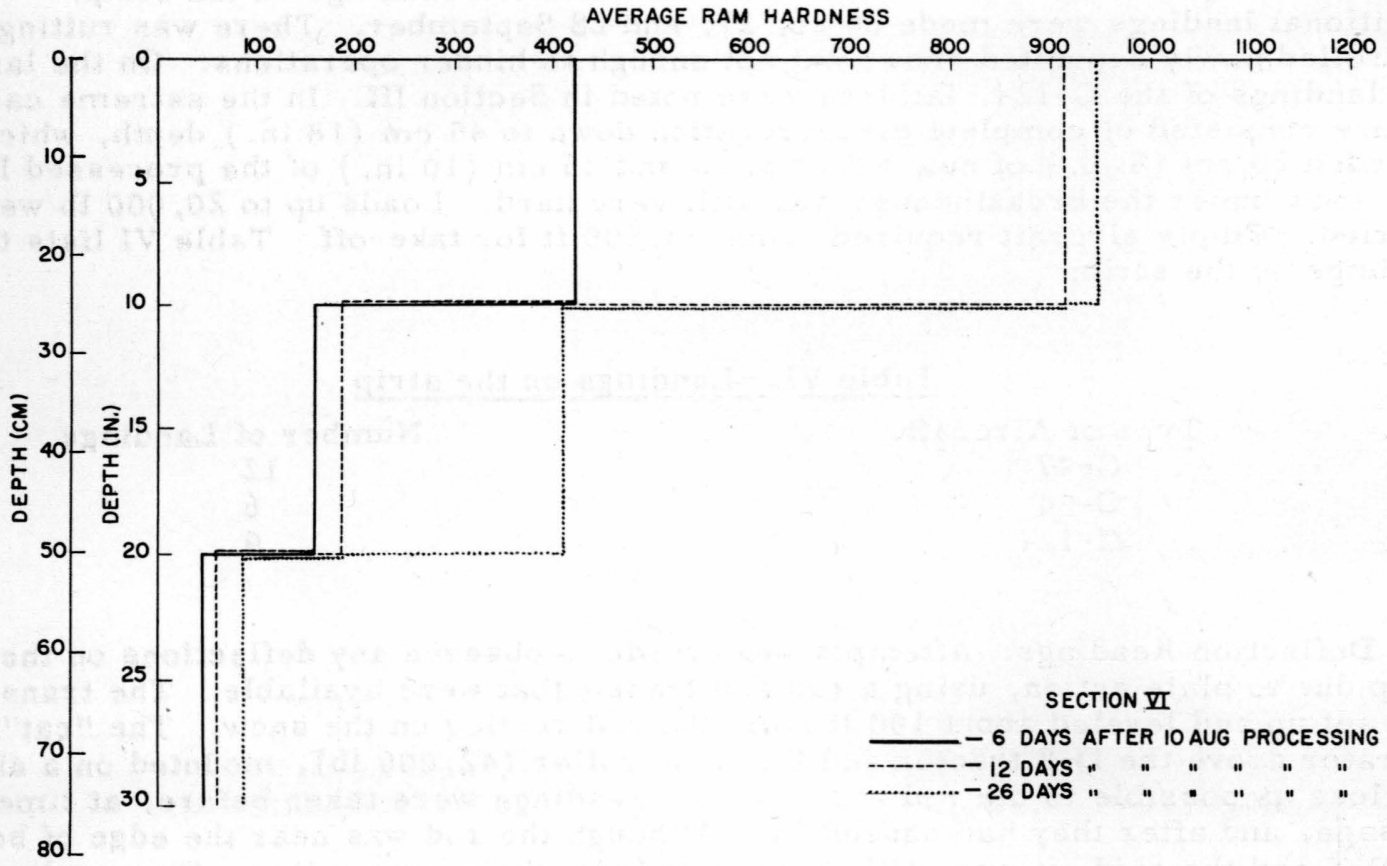

Figure 33. Average ram hardness by layer, Section VI. 


\section{Large-scale testing}

Large-scale testing of the strip was started 15 August, by pulling the fourwheeled rubber-tired Bros roller over the strip and increasing the total load to $42,000 \mathrm{lb}$, with the tire pressure at approximately $100 \mathrm{psi}$.

The strip failed very noticeably in Sections III and V. Section V became so bad that it was necessary to doublehead tractors to pull the roller out (Fig. 34 ). These two sections were then reprocessed.

On 27 August, the strip was tested by a ski-wheeled C-47 airplane. The plane first landed on skis nearby, taxied over to the strip, and took off empty using less than $2500 \mathrm{ft}$ of runway (Sections I and II). The plane then landed on wheels on Section I and II, taxied past Section III and into Section IV (about $3500 \mathrm{ft}$ ), turned a round and parked at about the $1500 \mathrm{ft}$ mark. A 3500-1b load was put on; the plane taxied the entire length of the strip and took off.

Inspection of the strip showed that Sections III and V were definitely rutted, and the pilot had to work the motors quite hard to get through Section V. A sketch of breakthroughs in sections III and V is shown in Figure 35 . It is very important to note that in no case was there failure by a punching of the top layer into the layer below. Because of the breakthroughs in Section V, the snow was removed, virgin snow was hauled in and received three passes of the pulvimixer with heat.

A C-54 type aircraft tested the strip on 10 September. It landed, taxied, and took off several times. The average roll on landing was about $3000 \mathrm{ft}$, take-off empty required about $2200 \mathrm{ft}$, and take-off with a $5000 \mathrm{lb}$ load required about $2600 \mathrm{ft}$. The pilots said that there we re no unusual problems in the landings and take-offs.

In several places, the C-54 plane broke through newly deposited and rolled snow to the top 'of the harder processed layer. However, in Section III, there were two minor failures in the processed layer, similar to that shown in Figure 35 (top). The depth of cohesionless snow in the breaks was less than $7 \mathrm{~cm}(3 \mathrm{in}$.$) and 5 \mathrm{~cm}$ ( 2 in. ).

On 25 September, a C-124 type aircraft made two landings on the strip. Additional landings were made on 26, 27, and 28 September. There was rutting of the rolled newly deposited snow, but not enough to hinder operations. On the last two landings of the C-124, failures were noted in Section III. In the extreme case, failure consisted of complete disaggregation down to $45 \mathrm{~cm}$ ( $18 \mathrm{in}$.) depth, which included $20 \mathrm{~cm}$ ( $8 \mathrm{in}$.) of new rolled snow and $25 \mathrm{~cm}$ (10 in.) of the processed layer. The snow under the breakthrough was still very hard. Loads up to 20,000 lb were carried. Empty aircraft required 4,000-4,500 ft for take-off. Table VI lists the landings on the strip:

Table VI. Landings on the strip

\begin{tabular}{lc}
\multicolumn{2}{c}{ Table VI. Landings on the strip } \\
\cline { 2 - 3 } Type of Aircraft & Number of Landings \\
C -47 & 12 \\
C -54 & 6 \\
C- -124 & 9
\end{tabular}

Deflection Readings: Attempts were made to observe any deflections on the strip due to plate action, using a rod and transit that were available. The transit was set up and leveled about $100 \mathrm{ft}$ from the rod resting on the snow. The "cat" operator drove the D-8 tractor and the Bros roller $(42,000 \mathrm{lb})$, mounted on a skid, as close as possible to the rod and past it. Readings were taken before, at time of passage, and after they had passed by. Although the rod was near the edge of both the D-8 and the skid, it was still about $10 \mathrm{ft}$ from their center line. The readings are given in Table VII. In no case did the observed deflection return to a zero reading. The size of the deflections are of the same order as the accuracy of the readings. It may therefore be considered that, if there are deflections, they are very small. 


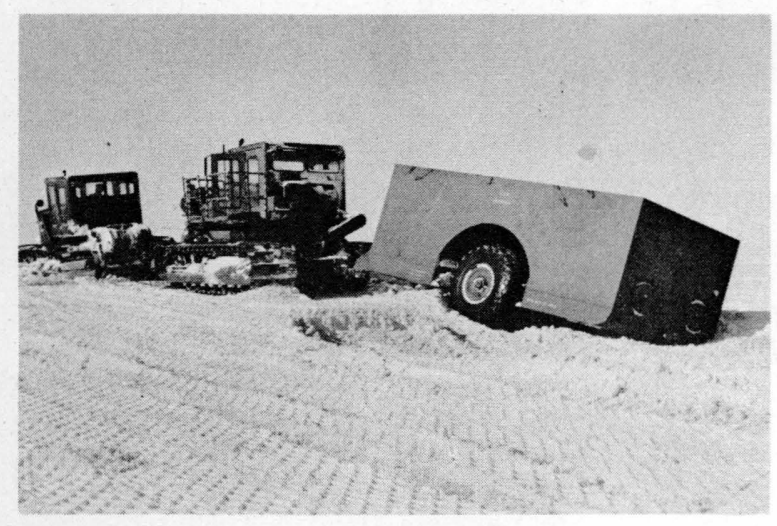

Figure 34. Tractors pulling Bros roller out of breakthrough.
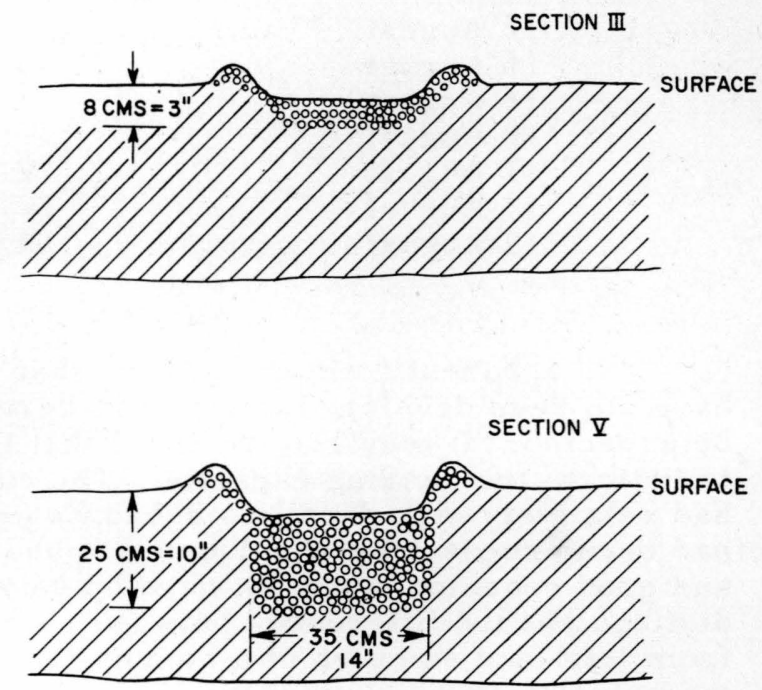

$$
\begin{aligned}
& \text { III/ - PROCESSED SNOW } \\
& \circ \circ-\text { COHESIONLESS SNOW } \\
& \circ 0^{-}
\end{aligned}
$$

Figure 35. Sketch of manner of surface failure.

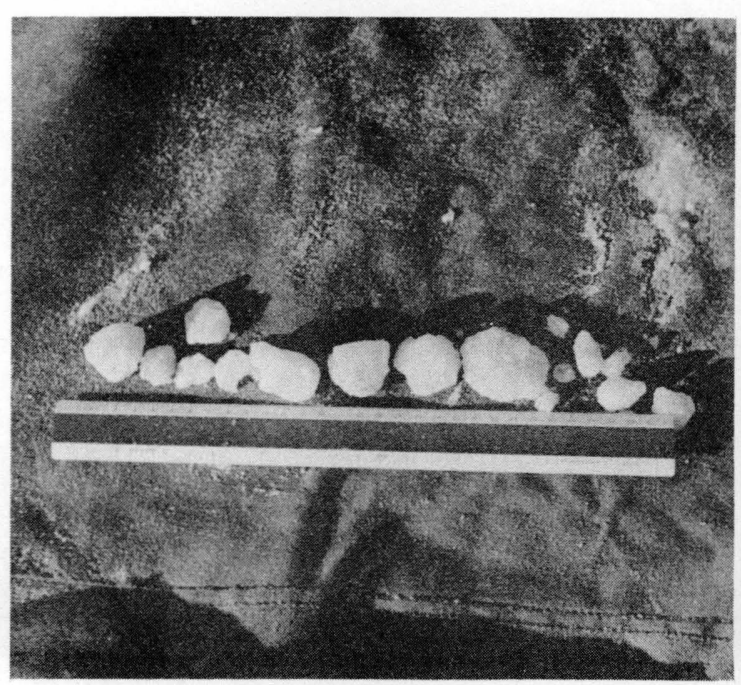

Figure 37. Large iced snow clumps from Section III.
Figure 36. Difference in homogeneity of samples from sections III and IV. 
Table VII. Deflection Readings

$\begin{array}{lcc}\text { Date } & \text { Section } & \text { Deflection (in.) } \\ 16 \text { August } & \text { VI } & 1 / 100 \\ 16 \text { August } & \text { VI } & 0 \\ 16 \text { August } & \text { IV } & 1 / 200 \\ 16 \text { August } & \text { IV } & 0 \\ 17 \text { August } & \text { IV } & 0 \\ 17 \text { August } & \text { IV } & 1 / 200 \\ 17 \text { August } & \text { VI } & \end{array}$

\section{DISCUSSION OF RESULTS}

It is apparent from the figures that the pulvimixer and the techniques of using it have not been developed to a point where a fairly homogeneous processed layer may be expected. It may also be noted that the density of the snow alone is not sufficient to indicate the bearing capacity. The extreme cases we re Sections III and V, which had relatively high densities but low strengths. This was mainly because the snow had been processed and subjected to heat so many times that icy clumps were formed and good cohesion could not develop between them. Figure 36 shows the readily distinguishable differences between samples taken from Section III (first and third from left) and samples of a homogeneous snow from Section IV. Figure 37 shows the actual size of a few of the larger clumps taken from Section III.

Figures 38-41 show a composite of the ave rage density, compressive strength, and ram values by layer for Sections III, IV, V, and VI. The ram hardness is for the same day that the density and strength values we re obtained.

Figure 42 shows a plot of the ram hardness versus the compressive strength with each point representing a large number of tests. The straight line $\underline{R}$ computed by means of least squares is:

$$
R=57+26 \sigma
$$

or, in terms of compressive strength:

$$
\sigma=0.04 \mathrm{R}-2.2 \text {, }
$$

if $\sigma$ is in $\mathrm{kg} / \mathrm{cm}^{2}$.

If $\sigma$ is in terms of psi, then:

$$
\sigma=0.57 \mathrm{R}-32.5 .
$$

For a ram hardness value of 57 or less there is no compressive strength. This is to be expected, as an entirely cohesionless material would give a Rammsonde reading and the strength values given here are for the unconfined case.

Test results published by the Directorate of Engineer Development (1953) on a shallow snow runway underlain by frozen ground indicate that an average ram hardness reading $(\underline{R})$ of 250 or over would support aircraft with pressures up to 65 psi. The Air Proving Ground Command (1954) tested a large number of aircraft including fighter planes having tire pressures up to $180 \mathrm{psi}$, although it is difficult to analyze their results because their runway was so shallow and contained up to $10 \%$ foreign material. A section of the runway with a ram hardness of over 500 supported a F84F fighter ( 150 psi) but a section with a reading below $250 \mathrm{R}$ failed. Tests in Greenland by the U. S. Naval Civil Enginee ring Research and Evaluation Laboratory (Moser, 1954) indicated that a 16-in. processed laye $\mathrm{r}$ with a $259 \mathrm{R}$ reading floating on virgin snow of $44 \underline{R}$, would not support a C-47 (60 psi) but a 
similar mat of $520 \mathrm{R}$ would support the C-47. Some of the Greenland 1955 test results are shown in Tables VIII and IX.

Table VIII. Average Ram Hardness Values of Processed Layer

\begin{tabular}{crrl} 
Section & \multicolumn{1}{c}{$\mathrm{R}$} & Date Taken & C-47 Landings 27 August \\
I & 765 & 22 August & Supported \\
II & 1226 & 22 August & Supported \\
III & 366 & 27 August & Failed in places \\
IV & 500 & 22 August & Supported \\
V & 174 & 25 August & Failed badly \\
VI & 916 & 22 August & Supported
\end{tabular}

Table IX. Average Ram Hardness Values of Processed Layer Landings

\begin{tabular}{|c|c|c|c|c|}
\hline Section & $\mathrm{R}$ & Date Taken & $\begin{array}{c}\text { C-54 } \\
10 \text { September }\end{array}$ & $\begin{array}{c}\text { C- } 124 \\
28 \text { September }\end{array}$ \\
\hline I & 1212 & 4 September & Supported & Supported \\
\hline II & 1469 & 4 September & Supported & Supported \\
\hline III & 604 & 5 September & Minor Failure & Minor Failure \\
\hline IV & 1261 & 5 September & Supported & Supported \\
\hline V & 627 & 5 September & Supported & Not tested \\
\hline VI & 946 & 5 September & Supported & Not tested \\
\hline
\end{tabular}

From Table VIII, it may be noted that sections with an average $\underline{R}$ of 500 or more supported a C-47, an average of 174 definitely would not, while Section III failed in places. A closer examination of the individual readings in this section disclosed that there was a Rammsonde reading of only 246 at the actual place of failure.

It appears from Table IX that a section with a $\mathrm{R}$-number of over 627 will support a $\mathrm{C}-54$. Again examination shows that the individual reading at the place of breakthrough in Section III was an average of only $190 \mathrm{R}$ for the top $15 \mathrm{~cm}$. It is much more difficult to ascertain the requirements of the C-124 because of the time differences between the ram hardness readings and the C-124 tests. However, an approximation would be that the same readings would apply for the C-124 as for the C-54 if the processed layer was thick enough.

A plot of known ram hardness values for a processed surface that supported or failed under various tire pressures in shown in Figure 43. The straight line (also shown on Figure 42 as $\underline{R}^{\prime}$ ) may be expressed by the following empirical equations:

$$
\sigma(p s i)=\frac{R}{2}-80
$$

or

$$
\sigma\left(\mathrm{kg} / \mathrm{cm}^{2}\right)=\frac{\mathrm{R}}{30}-5 .
$$

It should be realized that the values of compressive strength are for the unconfined case, while tires on a runway represent a confined case. Since the confined strengths are higher than the unconfined strengths, this represents a safety factor.

The making of a snow runway differs in many respects from making an earth runway. The Corps of Engineers can build a ground strip to support a bomber of 


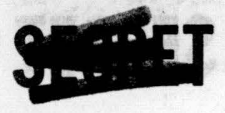

TESTING OF A COMPACTED SNOW RUNWAY
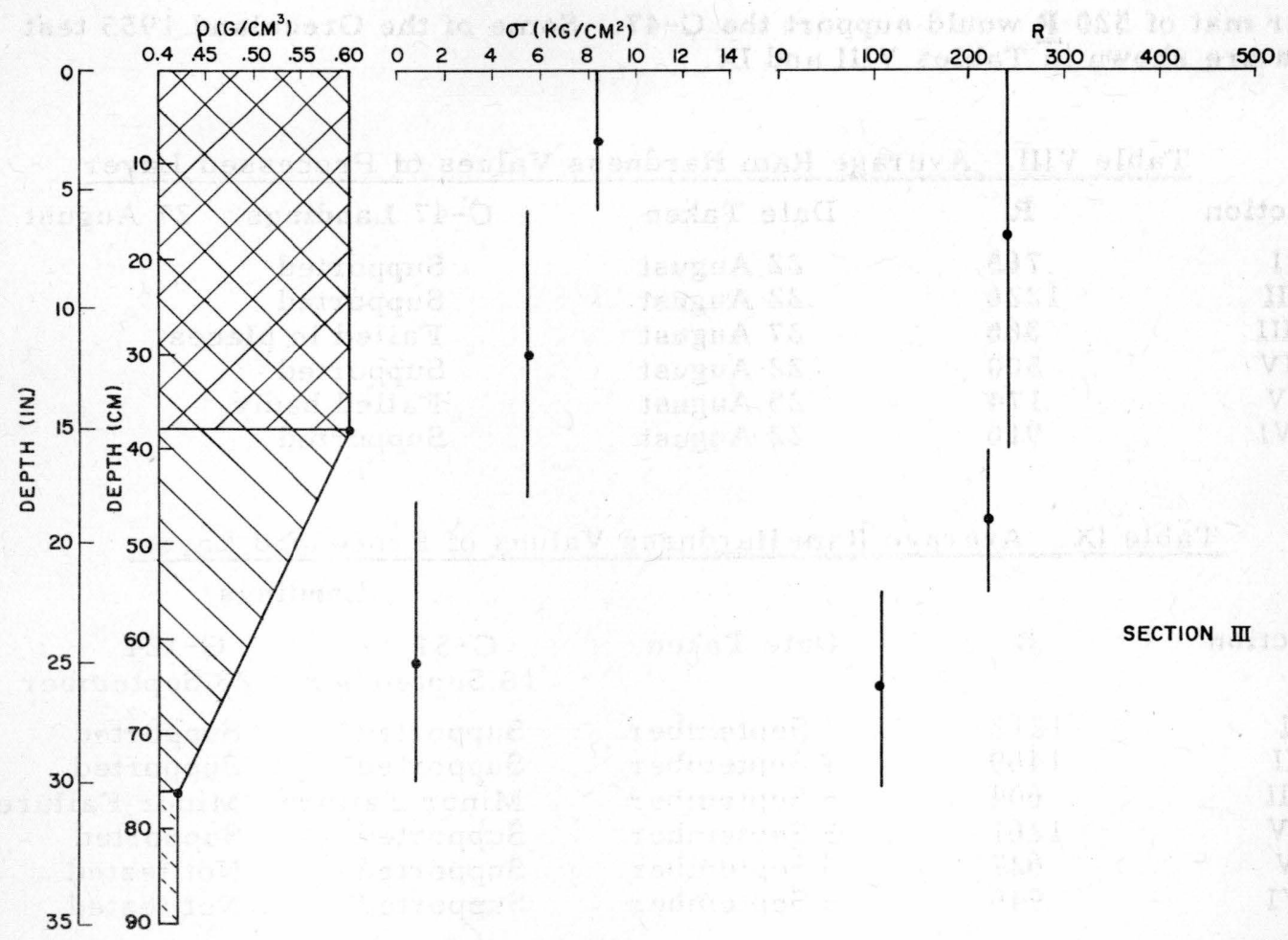

Figure 38. Average density, compressive strength, and ram hardness by layer, Section III.
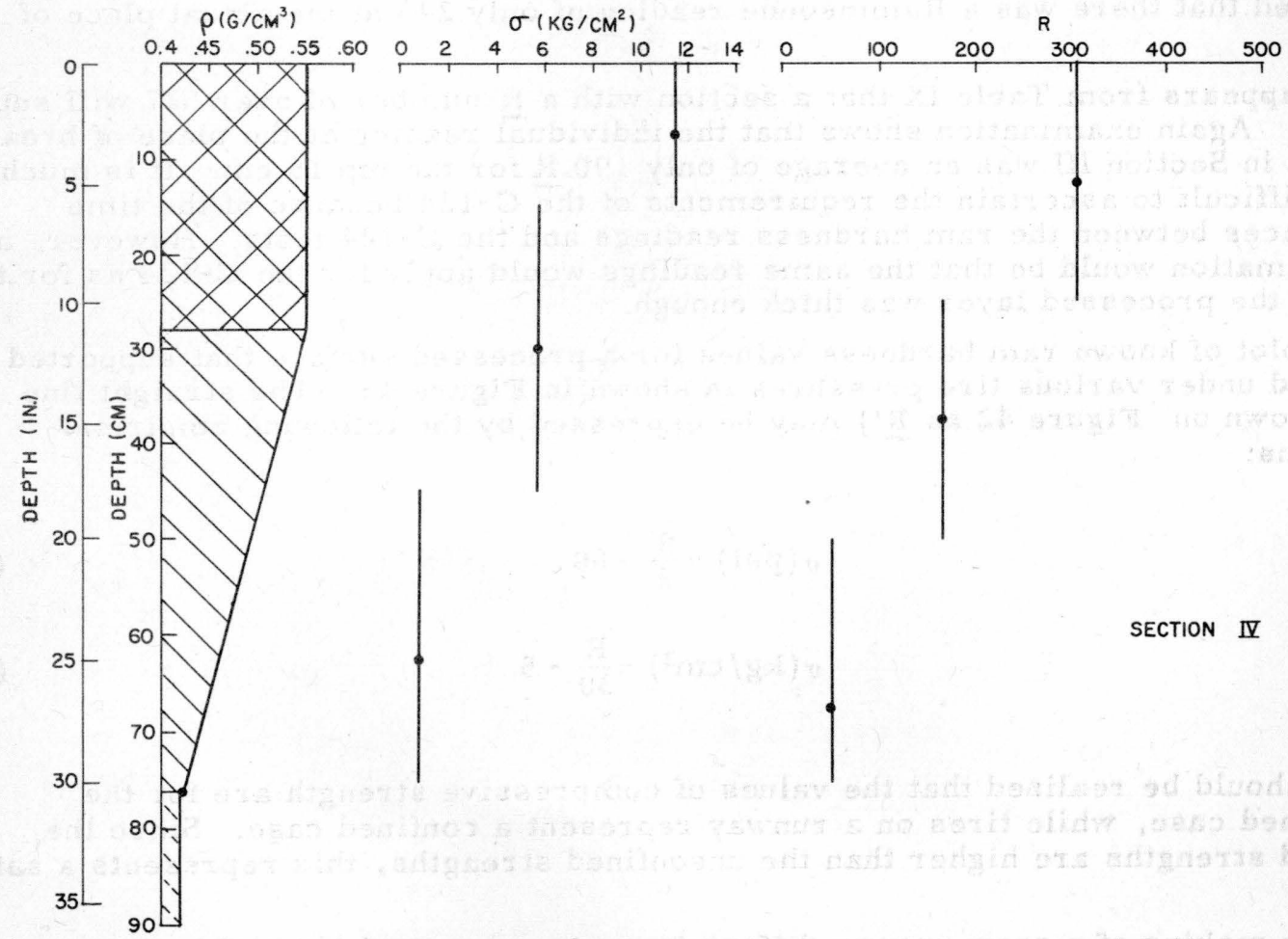

Figure 39. Average density, compressive strength, and ram hardness by layer, Section IV.

\section{Sr T}




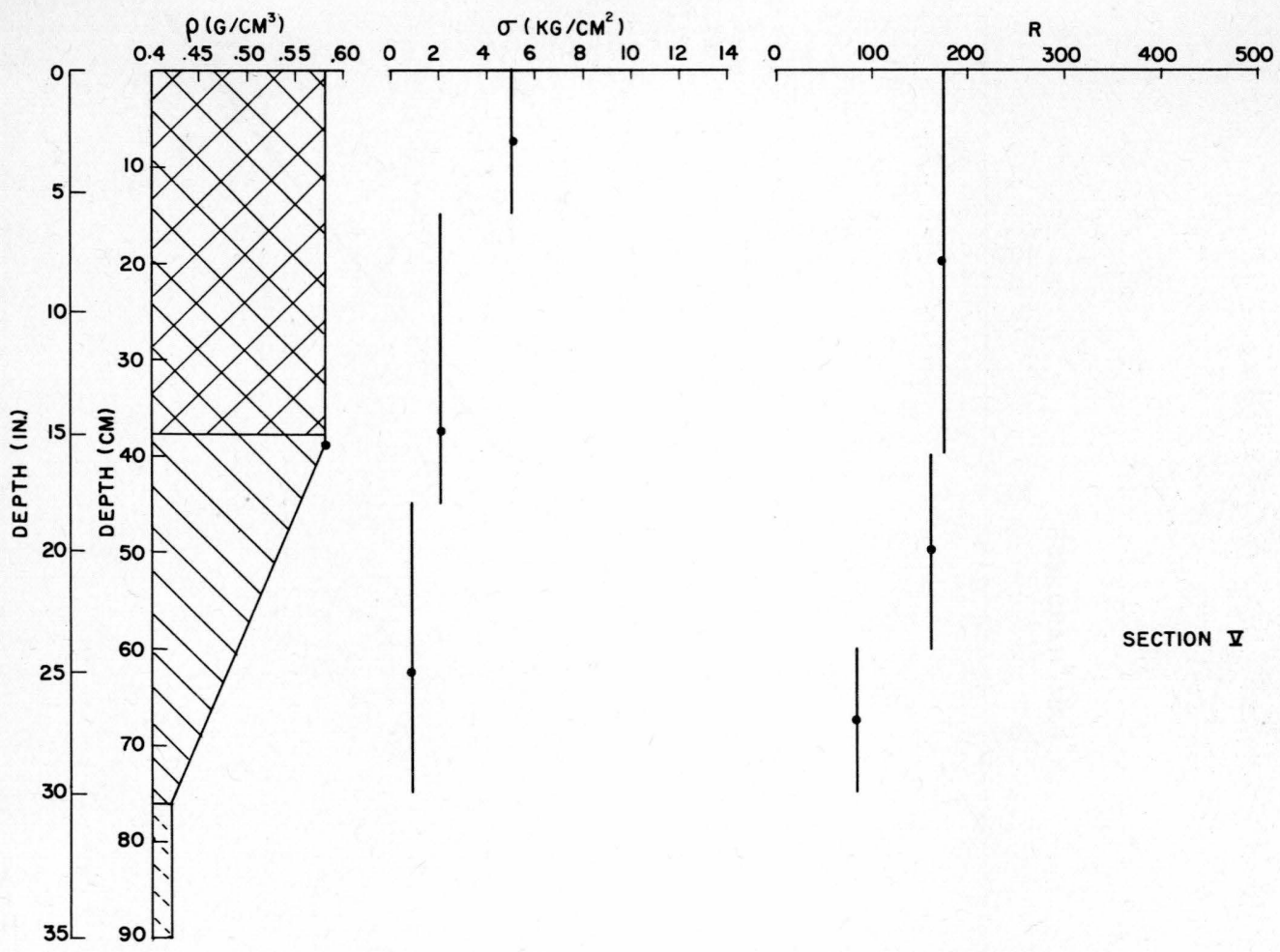

Figure 40. Average density, compressive strength, and ram hardness by layer, Section V.

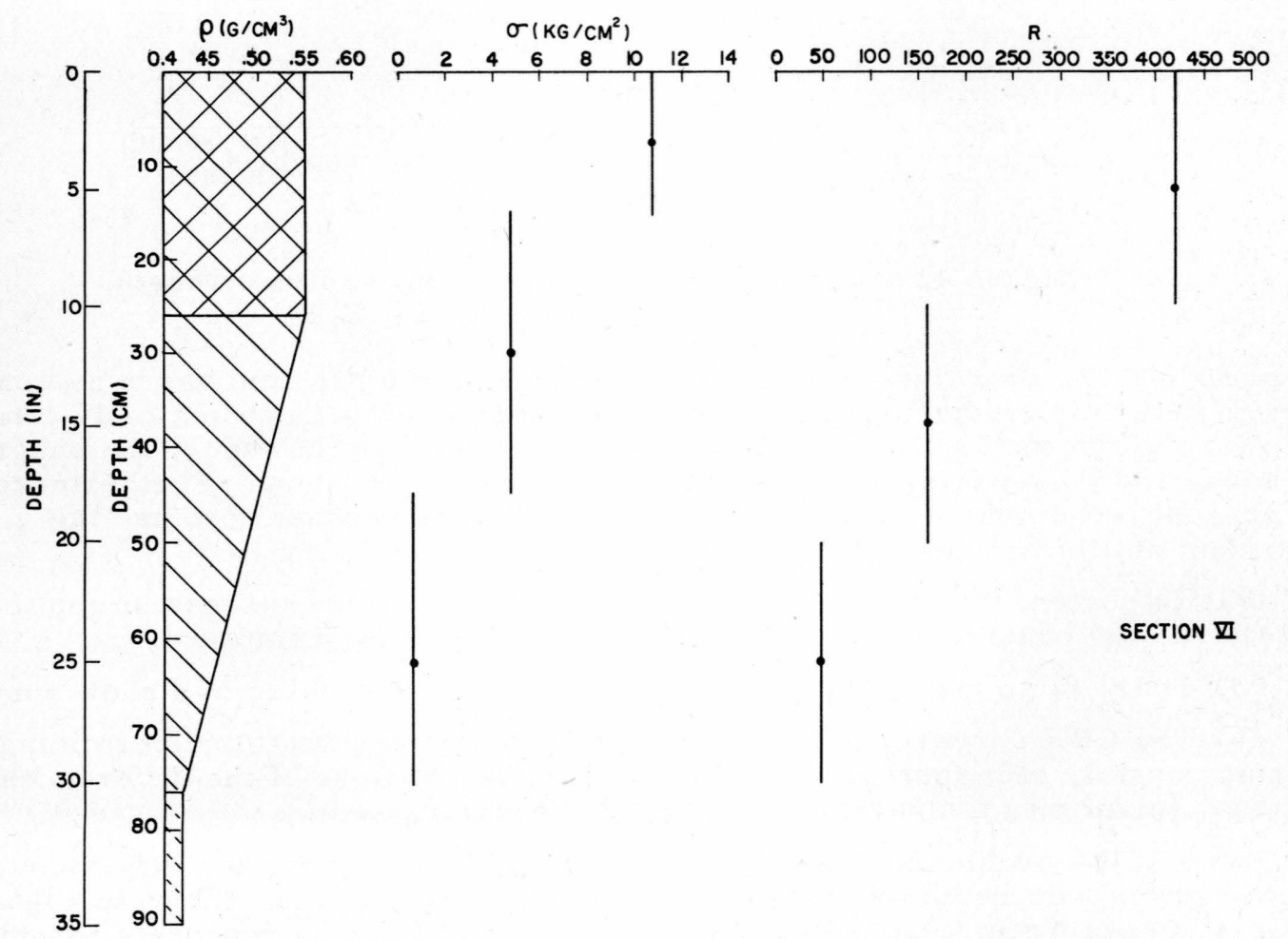

Figure 41. Average density, compressive strength, and ram hardness by layer, Section VI. 


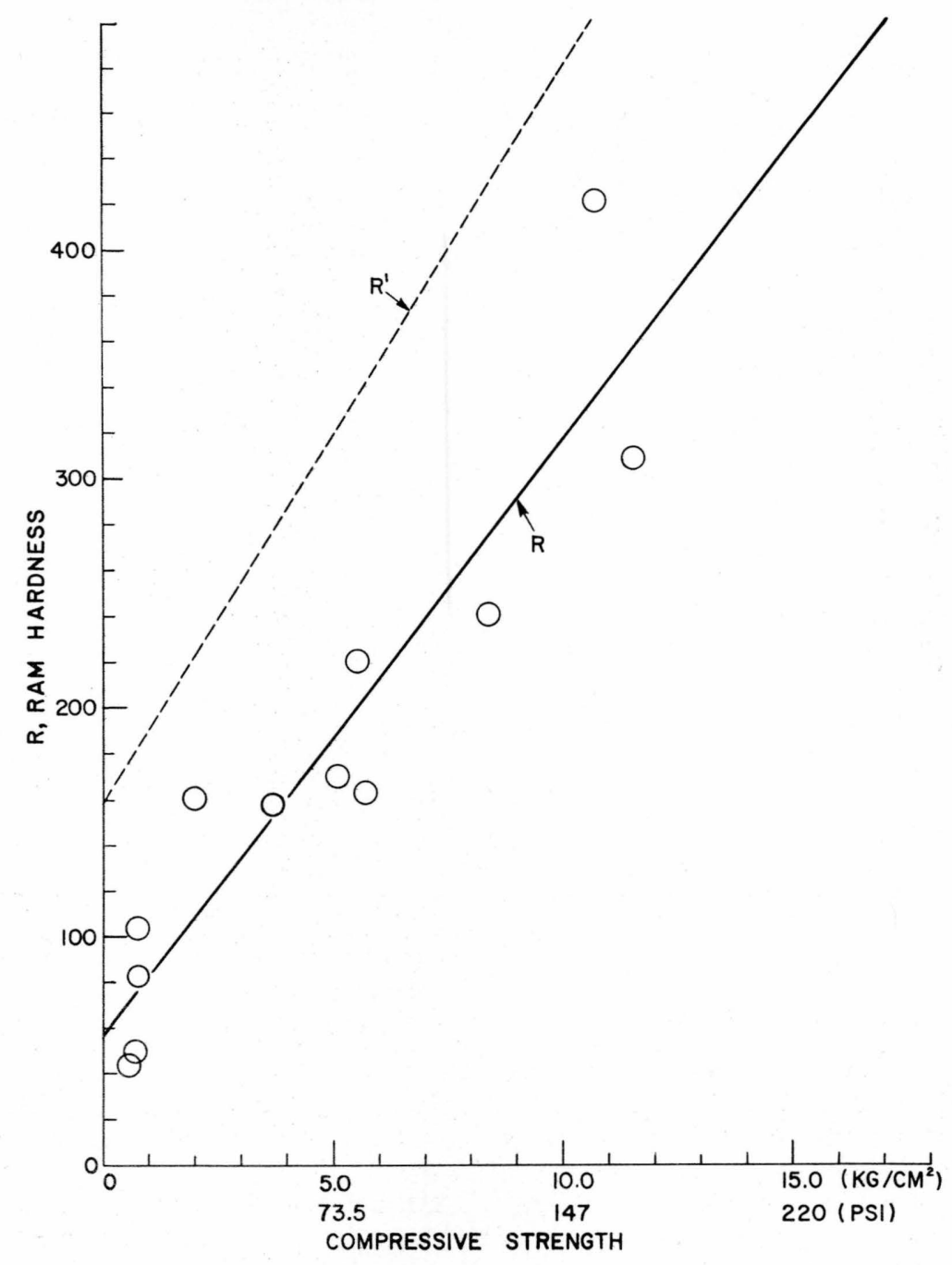

Figure 42. Ram hardness versus compressive strength. $R=57.2+25.8 \sigma ; R^{\prime}=157.2+32.2 \sigma$.

over $350,000 \mathrm{lb}$, or a fighter with tire pressures of $200 \mathrm{psi}$, and has done considerable work in determining the requirements for the best and most economically constructed strip for the operation required. On a high polar glacier, however, the subgrade, the base, and the wearing surface must all be made from snow. Furthermore, with the present techniques of making a snow runway, it is necessary to use the maximum ability because even this is just barely satisfactory.

It is important for people familiar with the CBR and its successful application to field runway construction to appreciate the differences, namely:

(a) There is no choice of material or degree of processing in a snow runway.

(b) The CBR curves presently available are not adequate for determining the bearing capacity of a snow runway once it is made, because of the differences in the material (plasticity, temperature effects, age hardening, etc.).

Some of the problems of a snow runway are clarified when the maximum vertical stress curves with depth are examined for various aircraft, as shown in Figure 44. These stresses were computed by approximating the tires as representing uniform circular loads and using the Boussinesq equation. It may be noted that, for the cargo 


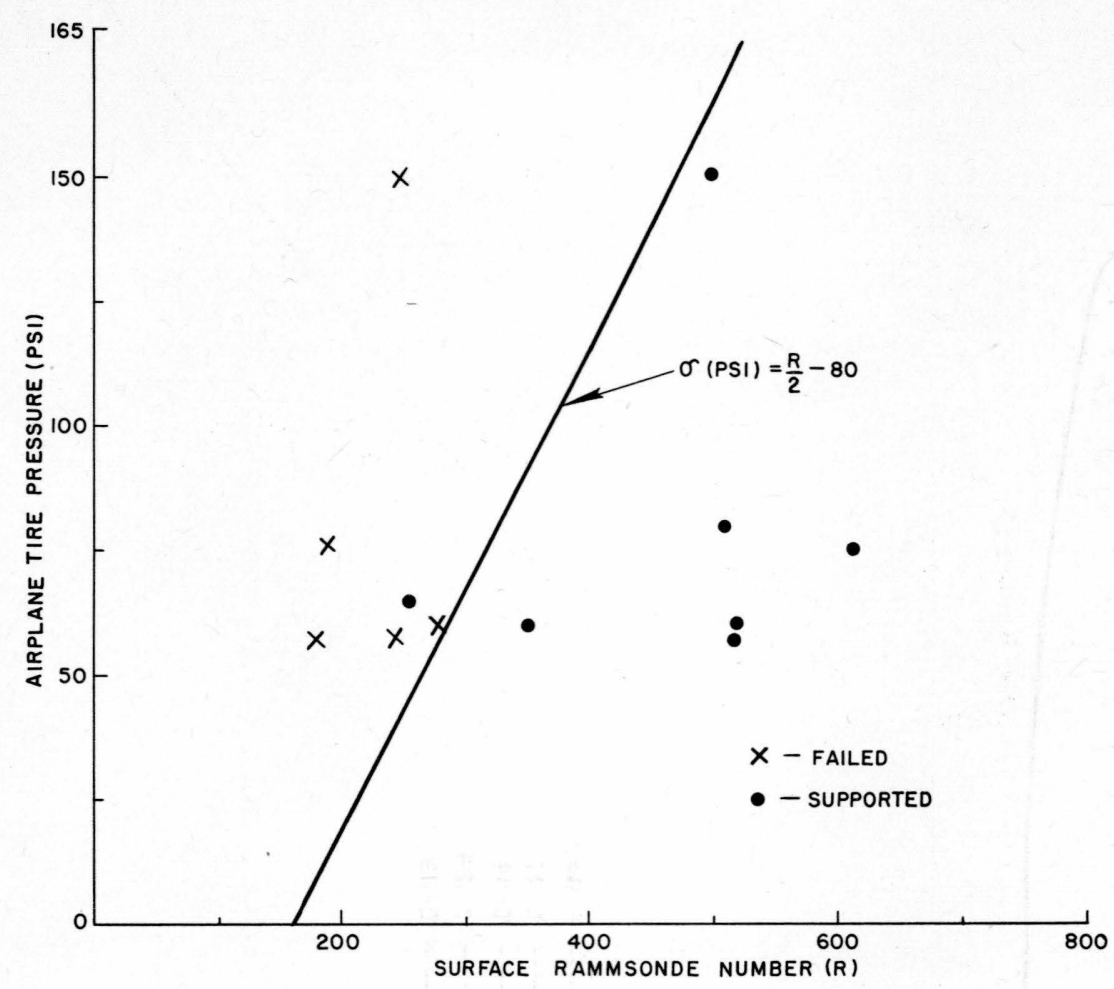

Figure 43. Ram hardness vs. support of failure of aircraft.

planes, a strong mat about $10 \mathrm{in.}(25 \mathrm{~cm})$ thick is required on top and, except for the $C-124$, the stress decreases very rapidly from $10 \mathrm{in.}$ on. It is necessary to have sufficient thickness of the processed layer so that the stress at the virgin snow layer will be less than its strength. It may also be noted that if a 5-in. $\left(12 \frac{1}{2}-\mathrm{cm}\right)$ layer of snow-ice or equivalent could be put on top of the pulvimixed surface, it would support small high-pressure tires (fighters and bombers).

For operational purposes, it is suggested that the Rammsonde be used as a simple test instrument. With Equations 4, 5 and Figure 44, showing the stress with depth curves, a strip may be easily tested with a Rammsonde to see if it is sufficiently strong to support a given aircraft.

\section{CONCLUSIONS}

The pulvimixer is at present the only piece of equipment in supply which, with modifications, can produce a processed snow runway. It is at best a marginal piece of military equipment, whose success is weather dependent. It is doubtful whether the 1955 Greenland strip would have been able to support aircraft if completed earlier and tested in July. There was a drop of over $19^{\circ} \mathrm{F}$ between the average July and September temperatures. This corresponds to an increase in strength of over $12 \%$ (see Appendix A). In 1954 there was a difference in average temperature of over $34^{\circ} \mathrm{F}$ between these two months, which corresponds to an increase in strength of $27 \%$. These temperature figures are of course for the Site 2 locality. If you go another 100 miles westward from Site 2 toward Thule, the mean annual temperature increases about $12^{\circ} \mathrm{F}$. 


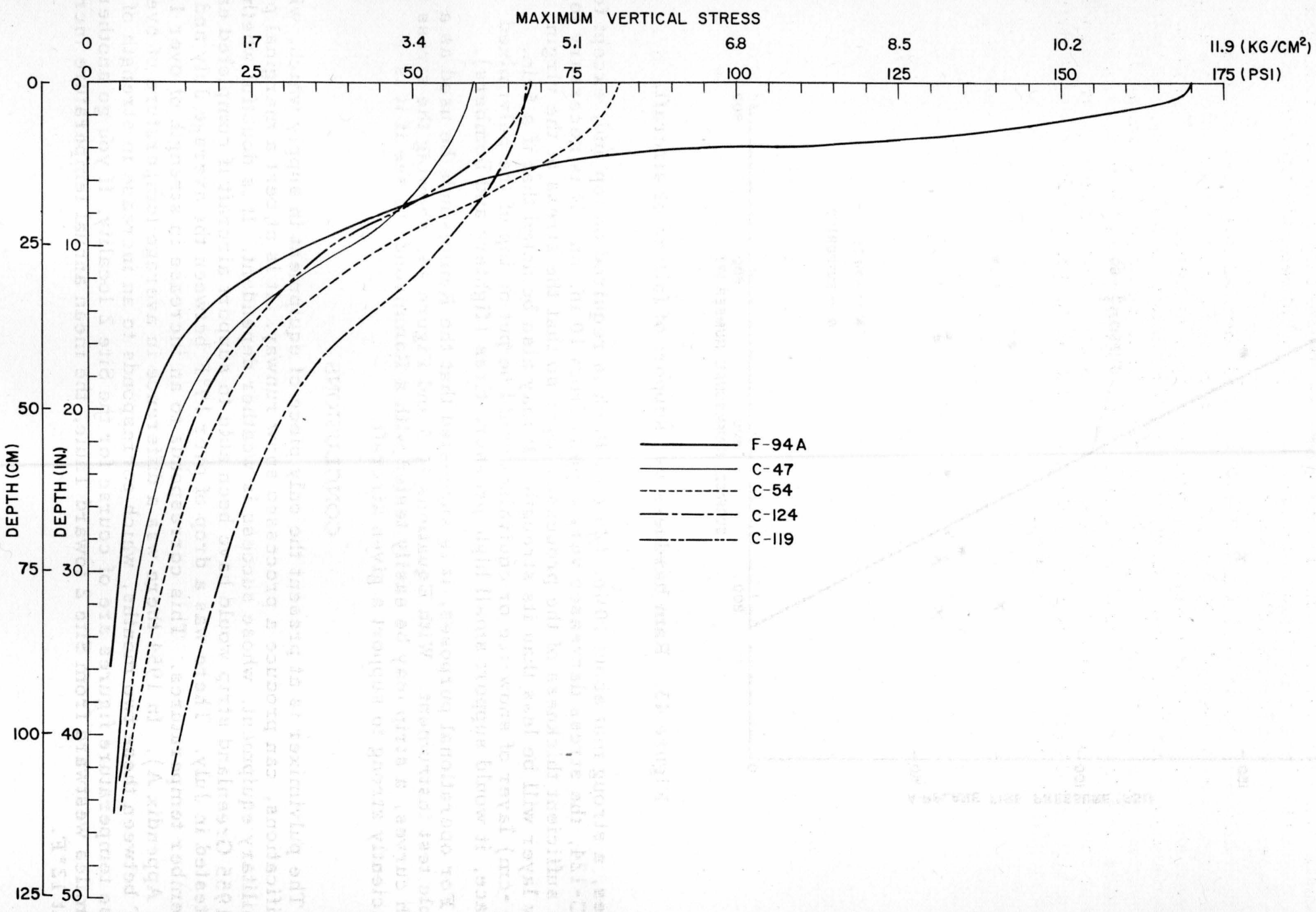

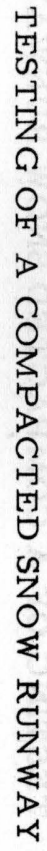

Figure 44. Stress distribution with depth of various aircraft. 
The strip would be improved by processing the entire length of the strip in one pass instead of by sections as was done in the 1955 summer season. Since it is desirable to have several passes in one lane, the processing should be done by a train of pulvimixers with a minimum amount of time between multiple passes on a given lane and turnarounds only at the end.

It is desirable to have as finely disaggregated snow as possible, in order to achieve maximum strength. Not much can be done with the present pulvimixer in this respect. The Engineer Research and Development Laboratories'T-4 snow packer and also the Peter snow plow tested by SIPRE have a milling type of action (high-speed rotating drum) and produce a much finer snow, and consequently should be able to make a stronge $r$ air strip. The possibility of putting on a hard surface layer of snow-ice should also be investigated. This could support planes with a high tire pressure and also would give a safety factor for the present strip, which is quite temperature-dependent. 


\section{APPENDIX A. \\ Effects of Temperature and Age-hardening on \\ the Strength of Snow}

Temperature effect

Quantitative data on the effect of temperature on the strength of snow is limited, although there is general agreement that "the colder the snow is, the stronger it is".

Bucher (1948) performed a series of experiments to determine the effect of grain size, density, and temperature on the tensile strength of low-density snows. Fuchs (1946) obtained a series of shear strength vs. temperature curves for screened snows of high densities. The Russians also have a curve on hardness vs. temperature (Buvert, 1951) with hardness measured by a surface cone penetrometer. Butkovich (1954) in his work on snow-ice found the crushing strength to have a temperature dependence similar to that obtained by Fuchs.

Almost all of the above data may be represented by the equation

$$
\log \frac{S_{2}}{S_{1}}=0.16 \log \frac{T_{2}}{T_{1}}
$$

where $S_{1}$ is the strength at $T_{1}$ centigrade and $S_{2}$ is the strength at $T_{2}{ }^{\circ} \mathrm{C}$. It is easier to use this in a graph form as shown in Figure Al by a series of parallel lines.

Example: If the strength at $-5^{\circ} \mathrm{C}\left(23^{\circ} \mathrm{F}\right)$ was 3.6 , what is the strength at $-30^{\circ} \mathrm{C}$ $\left(-22^{\circ} \mathrm{F}\right)$. Draw a line parallel, to those shown and passing through 3.6 at $-5^{\circ} \mathrm{C}$. The answer then is 4.8 at $-30^{\circ} \mathrm{C}$, in this case a $\frac{1}{3}$ increase in strength. Or, if a slide rule is handy: $\log S_{2}-\log 3.6=0.16 \log \frac{30}{5}$.

It was also pointed out by Bucher that the strength of a fine-grained snow is much more temperature-dependent than that of a coarse-grained snow. This is shown in Figure A2.

\section{Age-hardening}

A number of people (Bader et al. , 1939; Taylor, 1953; Kragelski and Shakhov, 1945; De Quervain, 1945; Shakhov, 1948) have suggested reasons for a given snow becoming harder with time, and the phenomenon has been observed by many people in the field. Nevertheless, there is very little quantitative information on the rate of age-hardening with time and as a function of temperature.

Although the term "hardness" or "hardening" is usually thought of in terms of resistance or increase of resistance to penetration, in snow it has come to indicate the corresponding increase in strength as well.

The author performed a series of investigations in the SIPRE laboratory using the work required to disaggregate a unit volume of snow as a measure of age hardening. A typical curve for a screened snow compacted to a density of 0.60 and allowed to harden at a temperature of $-5^{\circ} \mathrm{C}\left(22^{\circ} \mathrm{F}\right)$ is shown in Figure A3. Fuchs (1942) also ran a series of tests on screened snow, but used a direct shear test to measure the hardening. His curves are similar to the one shown in Figure A3, but he found a maximum increase in hardness at $-4^{\circ} \mathrm{C}\left(25^{\circ} \mathrm{F}\right)$. Fuchs also noted that fine-grained snow became harder than coarse-grained snow. The ratio of increase, i.e., strength at time of compaction/strength several days later, is shown in Figure A4, which represents the average of the SIPRE laboratory tests. - It should be noted that the case where the snow originally was wet is not considered. A good rule of thumb is to allow at least 3 days of hardening at moderate temperatures and about 4 to 5 days at low temperatures before strength tests or heavy traffic tests. 


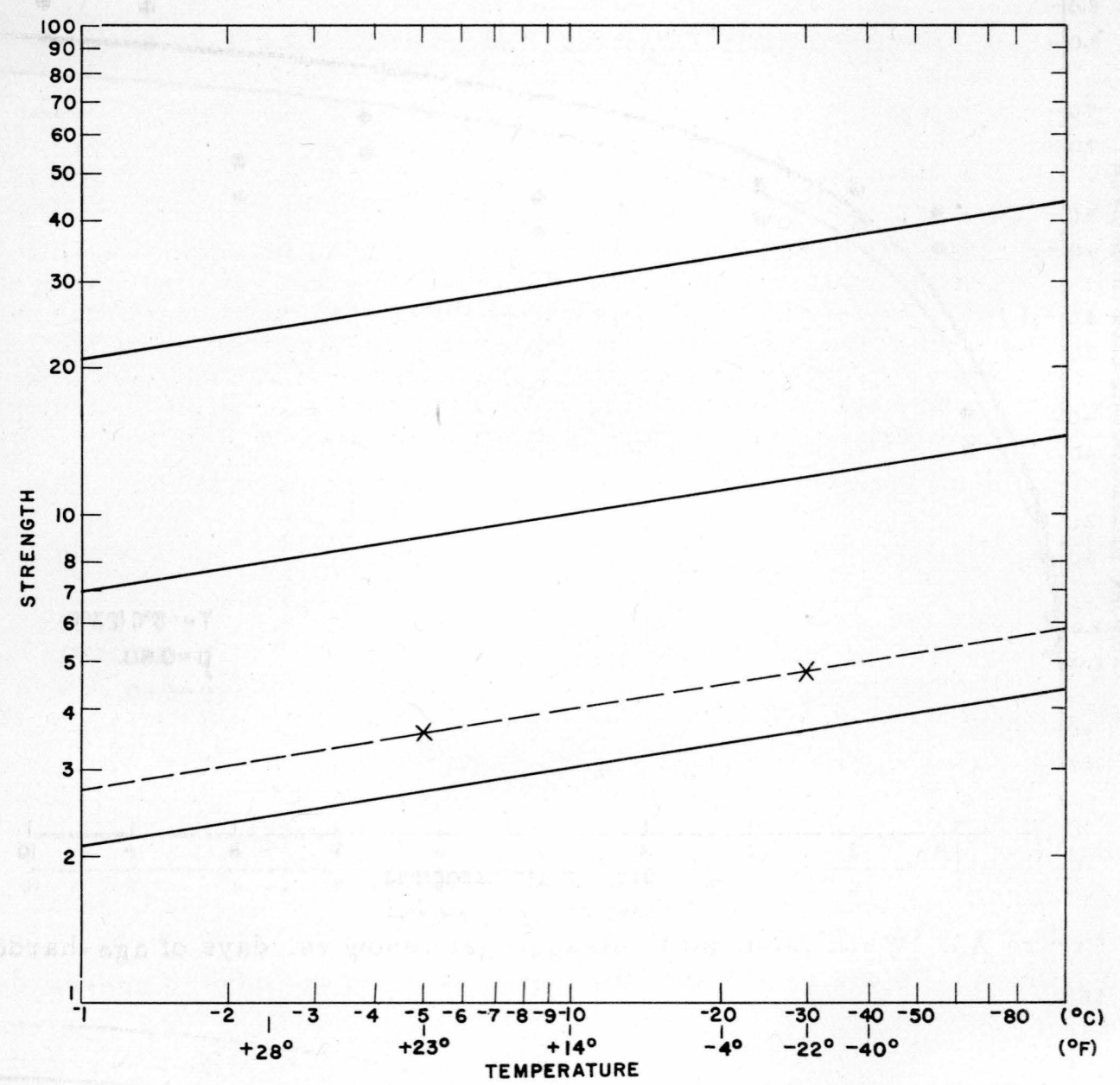

Figure Al. Strength vs. temperature plot on a $\log -\log$ scale.

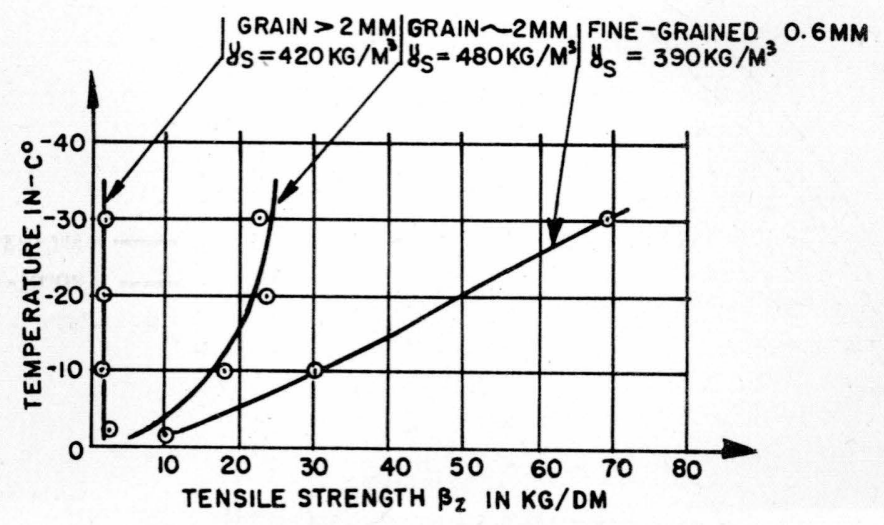

Figure A2. Temperature effect on tensile strength of various grained snow. (From Bucher, 1948) 


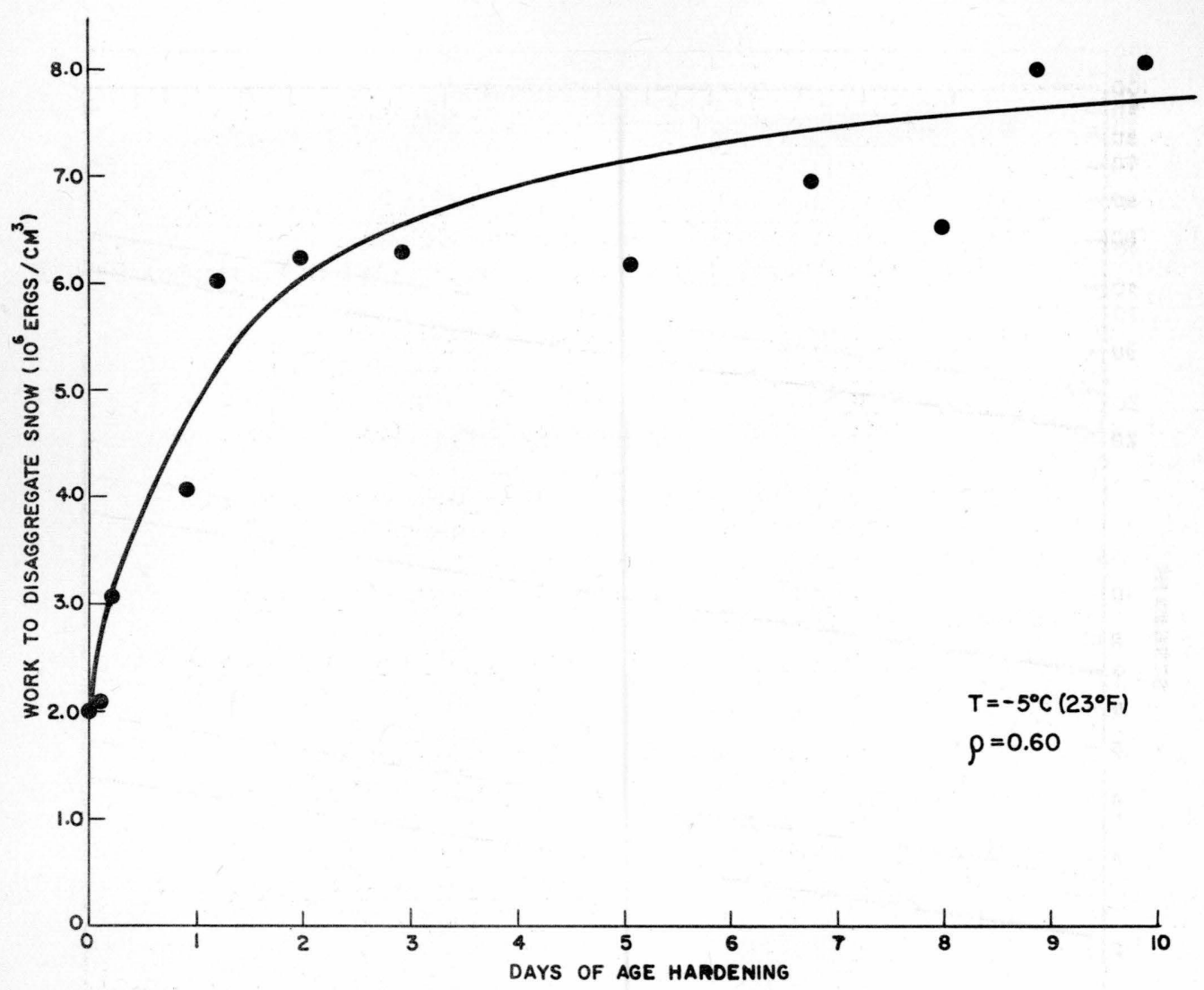

Figure A3. Work required to disaggregate snow vs. days of age-hardening.

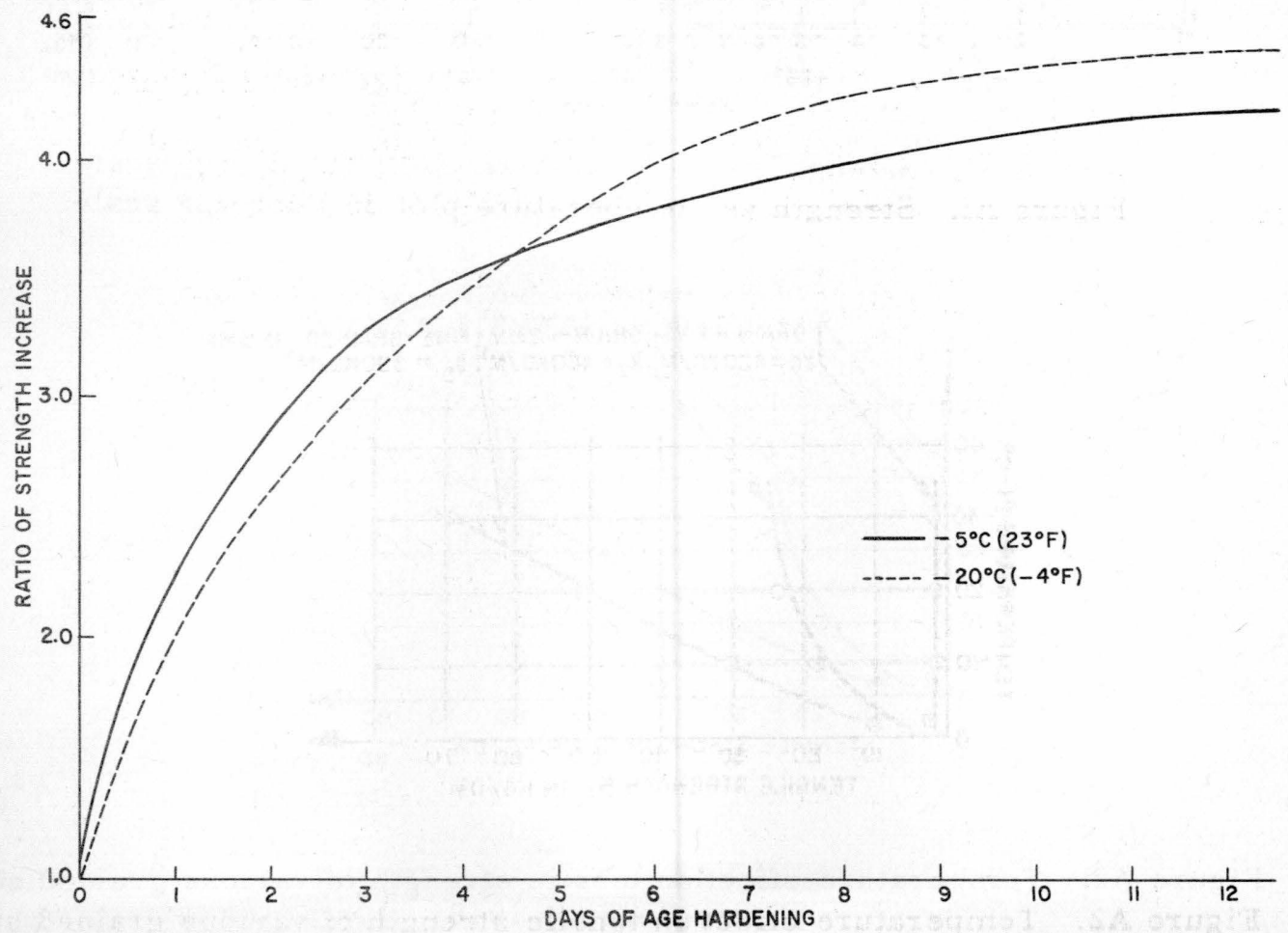

Figure A4. Ratio of strength increase vs. days of age-hardening. 


\section{REFERENCES}

Air Proving Ground Command (1954) Evaluation of compacted snow runways, Final Report on Proj. No. APG/CSC/277-C, Air Proving Ground Command, 62p. CONFIDENTIAL

Bader, Henri, et al. (1939) Der Schnee und seine Metamorphose (Snow and its metamorphism, Beitrage zur Geologie der Schweiz, Geotechnische Serie, Hydrologie, Lieferung 3, Bern (text in German). SIPRE Translation 14, 1954, 313p.

Bucher, Edwin (1948) Beitrag zu den theoretischen Grundlagen des Lawinenverbaus (Contribution to the theoretical foundations of avalanche defense construction), Beitrage zur Geologie der Schweiz, Geotechnische Serie, Hydrologie, Lieferung 6, Bern (text in German). SIPRE Translation 18, 1956, 109p.

Butkovich, T. R. (1955) Crushing strength of lake ice, Snow Ice and Permafrost Research Establishment, Corps of Engineers, U. S. Army, Research Paper 15, 5p.

Buvert, V. V. et al. (1951) Sukhoputnyi transport lesa (Overland hauling of logs), Moscow: Goslesbumizdat.

De Quervain, M. (1945) Schnee als kristallines Aggregat (Snow as a crystalline aggregate, Experientia, vol. l (Text in German). SIPRE Translation 21, 1954, 7p.

Directorate of Engineer Development (1954) Report on snow compaction trials, Winter 1952-53, Ottawa, Canadian Army, $241 \mathrm{p}$. SECRET

Fuchs, A. (1942) Uber Verfestigung von Lockerschnee durch Metamorphose in Abhangigkeit von Temperatur, Zeit und Korngestalt (Consolidation of loose snow by metamorphism as a function of temperature, time, and grain form), Versuchsber. 2, Ber. No. 241, Forschungsanstalt Graf Zeppelin, Stuttgart-Ruit, 16p. (Text in German). (1946) Die Scherfestigkeit von Schnee und Eis in Abhangigkeit von der Temperatur (The shear strength of snow and ice as a function of temperature), Ver offentl. Museum Ferdinandeum Innsbruck, vol. 26, p. 101-195, (Text in German).

Kragel'skii, I. V., and Shakhov, A. A. (1945) Izmenenie mekhanicheskikh svoistv Snegovogo pokrova vo vremeni (Change of mechanical properties of the snow cover as a result of time), in The Physical and mechanical properties of snow and their application in the consturction of airfields and roads, Moscow - Leningrad, Akademiia Nauk SSSR, p. 10-13 (Text in Russian).

Landauer, J. K. (1955) Stress-strain relations in snow under uniaxial compression, Snow Ice and Permafrost Research Establishment, Corps of Engineers, U. S. Army, Research Paper 12, 9p.

Moser, E. H. (1954) Technical report on Experimental Arctic Operation Hård Top 1953, U. S. Naval Civil Engineering Research and Evaluation Laboratory, Tech. Report R-006 (Project NY 000 003, 2, Snow compaction). SECRET

Shakov, A. A. (1948) Fizicheskie protsessy v snegovöm pokrove (Physical processes in a snow cover), Izvestiia Akademii Nauk SSSR, Seria geograficheskaia i geofizicheskaia, vol. 12, p. 239-248 (Text in Russian). SIPRE Translation 15, 1952, 17p.

Snow Ice and Permafrost Research Establishment (1951) Review of properties of snow and ice, Report 4, U. S. Army, Corps of Engineers, $156 \mathrm{p}$.

Taylor, Andrew (1953) Snow compaction, Snow Ice and Permafrost Research Establishment, Corps of Engineers, U. S. Army, Report 13. 64p.

Yamaji, Kenji, and Kuroiwa, Dai suke (1954) Shindoho ni yoru sekisetsu no dansei oyobi nensei no kenkvu (Studv of elastic and viscous properties of snow by the vibration method), Teionkagaku (Low Temp. Sci. ), Ser. A, vol. 13, p. 49-57 ( Text in Japanese with English summary). 


\section{APPENDIX B. \\ Preliminary Instructions for Determining whether a Specific Aircraft can Land Safely on a Given Compacted Airstrip}

The following instructions are based on the contents of this report. Until more data become available, the following criteria may be used.

Take a large number of ram hardness readings (a minimum of 20) on the entire strip. No testing should be done until 3 to 5 days after final processing, to allow the strip to age harden. If there are areas of discolored snow, these should receive extra testing, as they are likely to be weak. The following table lists the minimum ram hardness numbers at diffe rent depths acceptable for landing certain aircraft. Do not take the average of the ram readings, but only consider the lowest values.

This table is based on Figure 44 (stress distribution with depth of various aircraft) and Equation 4, relating ram values to compressive strength.

REQUIRED RAM HARDNESS VALUES WITH DEPTH

$\begin{array}{cccccr}\begin{array}{c}\text { Depth } \\ (\mathrm{cm})\end{array} & \text { F-94A } & \text { C-54 } & \text { C-119 } & \text { C-124 } & \text { C-47 } \\ 0-10 * & 170 & 108 & 100 & 100 & 94 \\ 10-15 & 430 & 310 & 284 & 290 & 272 \\ 15-20 & 300 & 296 & 274 & 288 & 264 \\ 20-25 & 260 & 280 & 260 & 280 & 256 \\ 25-30 & 220 & 252 & 240 & 270 & 240 \\ 30-35 & 210 & 234 & 226 & 264 & 224 \\ 35-40 & 196 & 224 & 212 & 252 & 210 \\ 40-45 & 190 & 214 & 208 & 236 & 200 \\ 45-50 & 184 & 210 & 200 & 230 & 296 \\ 50-55 & 180 & 206 & 190 & 224 & 290 \\ 55-60 & 176 & 200 & 186 & 216 & 186 \\ 60-65 & 174 & 196 & 182 & 212 & 184 \\ 65-70 & 160 & 180 & 170 & 200 & 172\end{array}$

* Required hardness readings in the surface layer $(0-19 \mathrm{~cm})$ are only $\frac{1}{3}$ of the true value, due to the cone effect.

Extra hardness in the upper $50 \mathrm{~cm}$ can make up for lescer hardness at greater depth, but quantitative recommendations on this matter can not yet be made.

The hardness of snow varies with temperature. A runway which was tested at low temperatures and found satisfactory should be retested if the temperature rises significantly, since it will have weakened. On the other hand, a runway tested at relatively high temperatures and found to be too weak may strengthen sufficiently for landings when the weather turns colder. 